\title{
The cytolytic molecules Fas ligand and TRAIL are required for murine thymic graft-versus-host disease
}

\author{
II-Kang Na, ${ }^{1,2}$ Sydney X. Lu, ${ }^{1}$ Nury L. Yim, ${ }^{1}$ Gabrielle L. Goldberg, ${ }^{1}$ Jennifer Tsai, ${ }^{1}$ Uttam Rao, ${ }^{1}$ \\ Odette M. Smith, ${ }^{1}$ Christopher G. King, ${ }^{1}$ David Suh, ${ }^{1}$ Daniel Hirschhorn-Cymerman, ${ }^{1}$ Lia Palomba, ${ }^{1}$ \\ Olaf Penack, ${ }^{1,2}$ Amanda M. Holland, ${ }^{1,3}$ Robert R. Jenq, ${ }^{1}$ Arnab Ghosh, ${ }^{1}$ Hien Tran, ${ }^{1}$ \\ Taha Merghoub, ${ }^{1}$ Chen Liu, ${ }^{4}$ Gregory D. Sempowski, ${ }^{5}$ Melissa Ventevogel, ${ }^{5}$ \\ Nicole Beauchemin, ${ }^{6}$ and Marcel R.M. van den Brink ${ }^{1}$
}

\begin{abstract}
1Department of Medicine and Immunology, Memorial Sloan-Kettering Cancer Center, New York, New York, USA. Department of Hematology and Oncology, Charité, Berlin, Germany. ${ }^{3}$ Department of Immunology, Weill Cornell Graduate School of Medical Sciences, New York, New York, USA.

${ }^{4}$ Department of Pathology, Immunology and Laboratory Medicine, University of Florida College of Medicine, Gainesville, Florida, USA. ${ }^{5}$ Human Vaccine Institute, Duke University School of Medicine, Durham, North Carolina, USA. ${ }^{6}$ Goodman Cancer Centre, Department of Biochemistry, Department of Medicine, and Department of Oncology, McGill University, Montreal, Quebec, Canada.
\end{abstract}

\begin{abstract}
Thymic graft-versus-host disease (tGVHD) can contribute to profound $\mathrm{T}$ cell deficiency and repertoire restriction after allogeneic BM transplantation (allo-BMT). However, the cellular mechanisms of tGVHD and interactions between donor alloreactive $T$ cells and thymic tissues remain poorly defined. Using clinically relevant murine allo-BMT models, we show here that even minimal numbers of donor alloreactive $T$ cells, which caused mild nonlethal systemic graft-versus-host disease, were sufficient to damage the thymus, delay $T$ lineage reconstitution, and compromise donor peripheral $\mathrm{T}$ cell function. Furthermore, to mediate tGVHD, donor alloreactive $T$ cells required trafficking molecules, including CCR9, $L$ selectin, $P$ selectin glycoprotein ligand-1, the integrin subunits $\alpha_{E}$ and $\beta_{7}, C C R 2$, and CXCR3, and costimulatory/inhibitory molecules, including Ox40 and carcinoembryonic antigen-associated cell adhesion molecule 1 . We found that radiation in BMT conditioning regimens upregulated expression of the death receptors Fas and death receptor 5 (DR5) on thymic stromal cells (especially epithelium), while decreasing expression of the antiapoptotic regulator cellular caspase-8like inhibitory protein. Donor alloreactive $T$ cells used the cognate proteins FasL and TNF-related apoptosisinducing ligand (TRAIL) (but not TNF or perforin) to mediate tGVHD, thereby damaging thymic stromal cells, cytoarchitecture, and function. Strategies that interfere with Fas/FasL and TRAIL/DR5 interactions may therefore represent a means to attenuate tGVHD and improve $T$ cell reconstitution in allo-BMT recipients.
\end{abstract}

\section{Introduction}

Allogeneic BM transplantation (allo-BMT) is a potentially curative therapy for a number of malignant and nonmalignant disorders. Myeloablative and nonmyeloablative conditioning regimens, which may contain radiation, chemotherapy, and immunosuppressive drugs, enable the engraftment of donor hematopoietic stem cells and prevent rejection by the host. Allo-BMT is frequently followed by a prolonged period of profound immune deficiency, which is associated with a high incidence of infection $(1,2)$ and malignant relapse (3).

Evidence from studies of patients receiving allo-BMT suggests that deficient $\mathrm{T}$ cell immunity in the first year after transplantation may be due to insufficient $\mathrm{T}$ cell numbers and restricted $\mathrm{T}$ cell repertoire and function (4). A broad $\mathrm{T}$ cell receptor repertoire requires the de novo generation of T cells in the thymus (5-7), and although thymic function in humans is age dependent and decreases after puberty (8-10), the adult thymus contributes substantially to immune reconstitution after allo-BMT (11).

Factors that inhibit thymic function after allo-BMT include thymic damage by the conditioning regimen $(9,12)$ and graft-ver-

Authorship note: Il-Kang Na and Sydney X. Lu contributed equally to this work. Conflict of interest: The authors have declared that no conflict of interest exists. Citation for this article: J. Clin. Invest. 120:343-356 (2010). doi:10.1172/JCI39395. sus-host disease (GVHD) mediated by donor alloreactive T cells $(13,14)$. Thymic GVHD (tGVHD) damages the architecture and composition of the thymic microenvironment $(13,15,16)$. Since effective development and normal $\mathrm{T}$ cell repertoire selection are critically dependent on a structured thymic microenvironment (17), tGVHD results in extended T lymphopenia, coupled with a restricted donor $\mathrm{T}$ cell repertoire and the appearance of clones with anti-host reactivity $(18,19)$. Thymic cellularity is reduced primarily because of a decrease in $\mathrm{CD}^{+} \mathrm{CD}^{+}$(double-positive [DP]) thymocytes, which occurs due to the failure of resident pro- and pre-T cells to enter the cell cycle as well as enhanced apoptosis of $\mathrm{CD}^{+}{ }^{+} \mathrm{CD} 8^{+}$thymocytes $(20,21)$.

Although Hollander and colleagues have previously suggested that thymic epithelial cells may be targeted by alloreactive donor T cells and damaged via IFN- $\gamma$, these studies were primarily done in a graft-versus-host reaction (GVHR) model system, without conditioning such as radiation or chemotherapy or with in vitro culture of thymic stromal cell lines (22). By contrast, the cellular and molecular mechanisms by which cytotoxic preparative regimens and acute GVHD mediated by donor alloreactive T cells cause damage, as well as the effects of conditioning on the thymus, have not been well studied, although Blazar and colleagues have previously shown that keratinocyte growth factor (KGF, palifermin) may be cytoprotective against tGVHD $(23,24)$. 
A

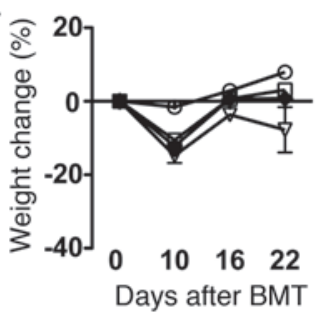

E

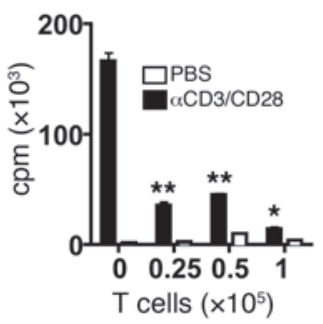

H

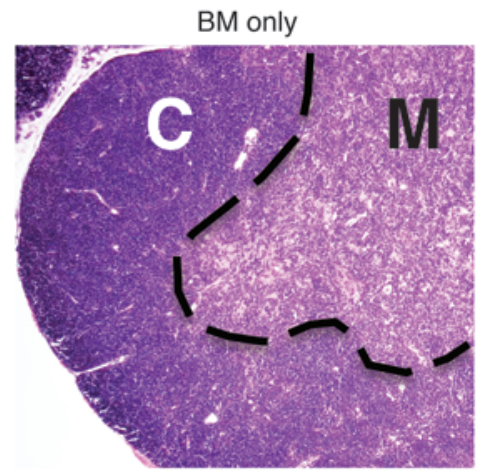

B

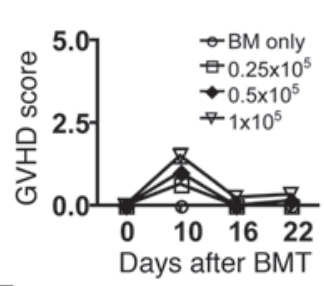

$\mathbf{F}$

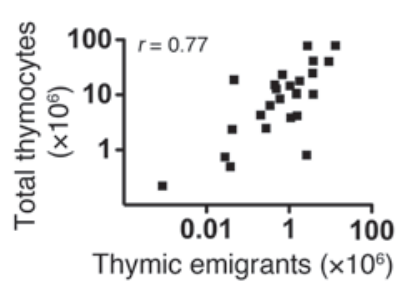

C

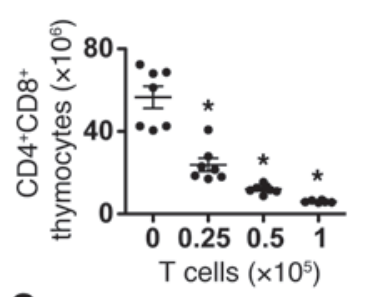

G

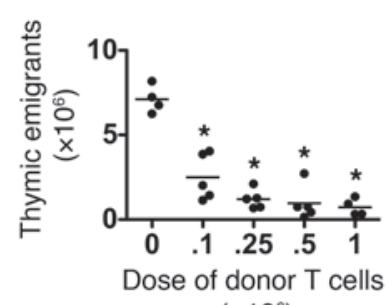

D

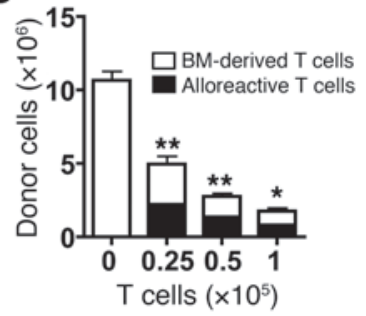

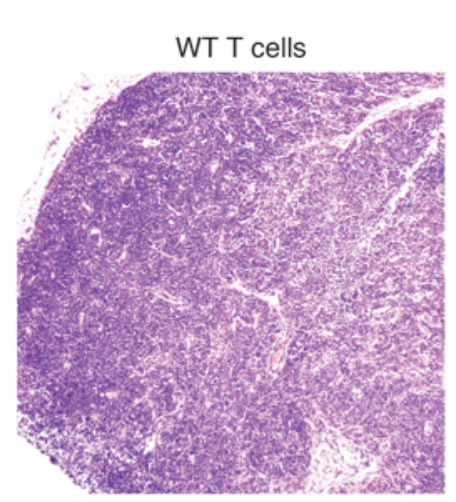

$\left(\times 10^{6}\right)$

I

\section{Figure 1}

Clinical GVHD correlates with tGVHD and thymic function of B6 $\rightarrow$ BALB/c (8.5 Gy) mice. (A) Weight loss and (B) GVHD score. $n=6-7 / g r o u p$. (C) Donor BM-derived CD4+CD8+ thymocyte numbers on day 22. Dots represent groups of animals. ${ }^{*} P<0.05$ versus TCD-BM control. $n=6-7 /$ group. (D) Total donor splenic T cells on day 22. ${ }^{*} P<0.05,{ }^{\star \star} P<0.001$ versus control; $P$ values are shown for donor BM-derived T cells. $n=6-7 /$ group. (E) Proliferation of splenic T cells after stimulation with anti-CD3 and anti-CD28 on day 22. ${ }^{*} P<0.05$, ${ }^{* *} P<0.001$ versus control. TCD-BM only and $0.25 \times 10^{5} \mathrm{~T}$ cells, $n=12 ; 0.5 \times 10^{5} \mathrm{~T}$ cells, $n=6 ; 1 \times 10^{5} \mathrm{~T}$ cells, $n=3$. (F) Linear regression of log-transformed thymic cellularity versus log-transformed splenic RTE numbers. Squares represent individual animals combined $(n=24)$ across all groups. One of two identical experiments is shown. $r$, regression coefficient. (G) RTEs versus the dose of donor T cells on day 42 after transplant. Dots represent individual animals. $n=4-5$ /group. ${ }^{*} P<0.05$ versus recipients of TCD-BM only. $(\mathbf{H})$ Histopathology (H\&E) of paraffin-fixed thymus sections on day 28 (no GVHD, BM only; GVHD, BM plus $0.25 \times 10^{6}$ WT T cells). The dotted line indicates the corticomedullary junction. C, cortex; M, medulla. Original magnification, $\times 50 . n=5$ /group. Representative sections are shown. (I) Quantification of cortical area (\% of total area) on day 28 . Average of 3 sections of each organ (50 $\mu \mathrm{m}$ apart). Symbols represent individual animals. $n=4-7 /$ group. ${ }^{*} P=0.01$ versus recipients of TCD-BM only. All horizontal bars indicate the mean. All values are mean \pm SEM.

Therefore, we undertake here an analysis in clinically relevant GVHD models to elucidate the development of tGVHD and the mechanisms by which allogeneic $T$ cells can infiltrate and damage the thymus. We first demonstrate the exquisite sensitivity of the thymus to damage by even very small numbers of donor alloreactive $T$ cells and then define the trafficking, coactivating or coinhibitory, cytotoxic molecules and cytokines relevant for these alloreactive T cells to cause tGVHD. Furthermore, we have used a clinically relevant radiation-dependent transplantation model to study the effects of radiation on thymic stroma and its impact on tGVHD.

\section{Results}

Donor alloreactive T cells are required for $t G V H D$ and damage the thymus in a dose-dependent manner. Mature donor T cells in the BM allograft are the primary initiators of acute GVHD, and disease severity cor- relates with the dose of donor $\mathrm{T}$ cells. We therefore began by characterizing the numbers of donor alloreactive $T$ cells in the allograft and their impact on systemic and tGVHD. We performed experiments in the well-defined MHC-disparate mouse model system $\mathrm{C} 57 \mathrm{BL} / 6\left(\mathrm{~B} 6, \mathrm{H}-2^{\mathrm{b}}\right) \rightarrow \mathrm{BALB} / \mathrm{c}\left(\mathrm{H}-2^{\mathrm{d}}\right)$. BALB/c recipients received 8.5 Gy radiation and an allograft containing $5 \times 10^{6}$ B 6 CD45.1 T cell-depleted BM (TCD-BM) cells and varying numbers of WT B6 CD45.2 T cells, which were insufficient to cause GVHD mortality. TCD-BM contained negligible numbers of contaminating $\mathrm{T}$ cells ( $0.1 \%$ cells; see Methods), and this process allowed for reliable titration of mature donor $\mathrm{T}$ cells in the allograft.

We assessed the sensitivity of the thymus to GVHD in experiments in which we titrated donor $T$ cell numbers and assessed the effect on systemic and tGVHD. We first used very low doses of donor alloreactive T cells $\left(0.25 \times 10^{5}, 0.5 \times 10^{5}\right.$, and $1 \times 10^{5}$ cells $)$, 
Table 1

Quantification of thymic cortical area

\begin{tabular}{|c|c|c|c|c|}
\hline & BM only & $0.5 \times 10^{5}$ & T cells & $25 \times 10$ \\
\hline No. of thymi analyzed & 5 of 5 & 9 of 9 & 7 of $9^{A}$ & 4 of $9^{A}$ \\
\hline $\begin{array}{l}\text { Loss of corticomedullary } \\
\text { junction }(n)\end{array}$ & 0 & 0 & 2 & 5 \\
\hline Mean cortical area (\%) & 73.8 & 70.1 & $63.6^{\mathrm{B}}$ & $52.7^{\mathrm{B}}$ \\
\hline SD & 2.9 & 5.5 & 6.2 & 9.4 \\
\hline SEM & 1.3 & 1.7 & 2.4 & 4.7 \\
\hline
\end{tabular}

ASome thymi were not analyzed because loss of corticomedullary junction precludes accurate determination of the cortical and medullary areas. ${ }^{\mathrm{B}} P<0.05$ versus TCD-BM only.

which caused recipients to exhibit negligible weight loss (Figure 1A) or clinical GVHD (Figure 1B); by comparison, mice experiencing severe GVHD and resulting mortality can have weight loss of more than $50 \%$ and clinical scores of greater than 7 (25). We then assessed thymic cellularity at week 4 after transplant and observed a striking dose-dependent decrease in donor BM-derived $\mathrm{CD}^{+}{ }^{+} \mathrm{CD} 8^{+}$thymocytes, with an approximately $50 \%$ loss, even with the addition of only 25,000 donor $\mathrm{T}$ cells (Figure 1C). We confirmed these results in additional experiments with $2.5 \times 10^{5}$ and $1 \times 10^{6}$ donor $\mathrm{T}$ cells, which also revealed an inverse relationship between thymocyte count and numbers of donor alloreactive $\mathrm{T}$ cells (data not shown). Upon monitoring recipients for survival, we noted that all mice receiving $0.25 \times 10^{6}$ or fewer donor $\mathrm{T}$ cells in the allograft had more than $95 \%$ survival up to day 28 after transplant. Survival for mice receiving $0.25 \times 10^{6}$ donor $\mathrm{T}$ cells is shown in Supplemental Figure 2 (supplemental material available online with this article; doi:10.1172/JCI39395DS1).

We also tested our findings in the MHC-matched minor antigen-disparate model system $\mathrm{B} 6\left(\mathrm{H}-2^{\mathrm{b}}\right) \rightarrow \mathrm{LP}\left(\mathrm{H}-2^{\mathrm{b}}\right)$ and added different doses of $\mathrm{B} 6$ Thy $1.1^{+} \mathrm{T}$ cells (to distinguish between donor BM-derived cells, infused alloreactive T cells, and host cells) to induce varying degrees of GVHD.

In several experiments, we observed again dose-dependent decreases of donor $\mathrm{CD}^{+} \mathrm{CD}^{+}$(DP) thymocytes at days 27 and 42 after transplant, in the absence of significant signs of clinical GVHD (including weight loss) (Supplemental Figure 3).

Although the kinetics of GVHD onset and the frequency of alloreactive $\mathrm{T}$ cells differ in this $\mathrm{MHC}$-matched minor antigen-disparate model, as compared with the $\mathrm{B} 6 \rightarrow \mathrm{BALB} / \mathrm{c}$ model in which we performed most of our experiments in this report (described below), these observations confirm the sensitivity of the thymus to GVHD in clinically relevant model systems.

Recipients of low doses of donor alloreactive $T$ cells exbibit $t G V H D$ that is partially reversible at later time points. To assess whether tGVHD is reversible, we repeated experiments in the model system $\mathrm{B} 6 \rightarrow \mathrm{BALB} / \mathrm{c}$ with $\mathrm{TCD}-\mathrm{BM}$ with or without $0.5 \times 10^{5}$, $1 \times 10^{5}$, or $2.5 \times 10^{5} \mathrm{~T}$ cells and assessed thymic cellularity and composition at day 60 after transplant. We observed that total thymocyte numbers were significantly decreased $(P<0.05)$ in recipients of TCD-BM plus $2.5 \times 10^{5} \mathrm{~T}$ cells versus recipients of TCD-BM only (Supplemental Figure 4A). However, at lower donor $\mathrm{T}$ cell doses, we observed a recovery of thymus cellularity at day 60 (Supplemental Figure 4, A and B) compared with day 28 (Figure 1C). These data suggest that recipients of low doses of donor alloreactive $\mathrm{T}$ cells may have partially reversible GVHD. However, recipients of higher doses of T cells may have more prolonged thymic damage.

In addition to analyzing thymic cellularity and composition in recipients of TCD-BMT and T cell-replete allo-BMT, we tracked their clinical GVHD parameters and weight loss, to correlate tGVHD with systemic and clinical GVHD to day 60 after transplant (Supplemental Figure 4, C and D). These data show that recipients of $\mathrm{T}$ cell-replete allografts with up to $2.5 \times 10^{5}$ donor $T$ cells developed partially reversible tGVHD, which was nonetheless correlated with low levels of sustained systemic GVHD.

These data suggest that recipients of low doses of donor alloreactive T cells may have partially reversible GVHD. However, recipients of higher doses of $\mathrm{T}$ cells may have more prolonged thymic damage.

GVHD damages thymic architecture, thymic output, and negatively influences peripheral $T$ cell function. We further studied the relationship between $\mathrm{tGVHD}$ and peripheral donor-derived $\mathrm{T}$ cell function in recipients of $5 \times 10^{6} \mathrm{TCD}-\mathrm{BM}$ with or without $0.25 \times 10^{5}, 0.5 \times 10^{5}$, and $1 \times 10^{5}$ alloreactive $\mathrm{T}$ cells. This revealed an inverse relationship between numbers of peripheral BM-derived $\mathrm{CD} 45.1^{+} \mathrm{T}$ cells and numbers of donor alloreactive $\mathrm{T}$ cells that were infused (Figure 1D). Surprisingly, infusing greater numbers of donor CD $45.2^{+}$ alloreactive $T$ cells did not lead to increased numbers of CD $45.2^{+}$ alloreactive $T$ cells in the spleens at day 22 after transplant (Figure 1D). This may be due to the fact that after day 14 of an allo-BMT, the spleen assumes features of a GVHD target organ; decreased cellularity may therefore be interpreted as increased damage. Finally, we noted that all groups had $90 \%$ or greater total donor chimerism in the spleen, as measured by $\mathrm{H}-2^{\mathrm{b}}$ staining (data not shown).

As donor BM-derived and alloreactive $\mathrm{T}$ cells can both mediate antipathogen and antitumor activity, we studied the function of all donor-derived peripheral $\mathrm{T}$ cells by purifying them with $\mathrm{CD}^{+}$ magnetic selection from the spleens of allo-BMT recipients on day 22 and testing the proliferation of these T cells with anti-CD3 and anti-CD28 stimulation. This revealed that donor-derived splenic $\mathrm{T}$ cells in recipients of TCD-BM only had significantly better proliferative responses upon anti-CD3 and anti-CD28 stimulation than recipients of TCD-BM and alloreactive donor T cells (Figure 1E).

To further study whether thymic cellularity was directly associated with thymic function (i.e., export) after T cell-replete allo$\mathrm{BMT}$, we transplanted irradiated BALB/c mice with $5 \times 10^{6} \mathrm{FVB}$ background Rag2-EGFP TCD-BM only or Rag2-EGFP TCD-BM plus $0.1 \times 10^{6}, 0.25 \times 10^{6}, 0.5 \times 10^{6}$, or $1 \times 10^{6}$ WT FVB T cells. Recent thymic emigrants (RTEs) are Rag2 ${ }^{+}$and therefore $\mathrm{EGFP}^{+}$in this model, thereby allowing for their identification in the periphery of the allo-BMT recipients. In addition to observing decreased thymic cellularity with increasing doses of donor $\mathrm{T}$ cells (data not shown), we also observed that, upon pooling data from all alloBMT recipients transplanted with varying doses of donor $\mathrm{T}$ cells, including mice which received BM only (no GVHD) or mice which received $0.1 \times 10^{6}, 0.25 \times 10^{6}, 0.5 \times 10^{6}$, or $1 \times 10^{6} \mathrm{FVB} T$ cells (varying degrees of tGVHD and thymic cellularity), absolute numbers of splenic RTEs correlated well with thymic cellularity (Figure 1F).

Additionally, we directly assessed the impact of increasing numbers of donor alloreactive $T$ cells (thus increasing severity of tGVHD) on thymic export by transplanting irradiated B6D2F1 mice (13 Gy) with $10^{5}$ Rag2-EGFP lineage ${ }^{-}$cells with or without $0.1 \times 10^{6}, 0.25 \times 10^{6}, 0.5 \times 10^{6}$, or $1 \times 10^{6} \mathrm{FVB} \mathrm{T}$ cells. We 
A
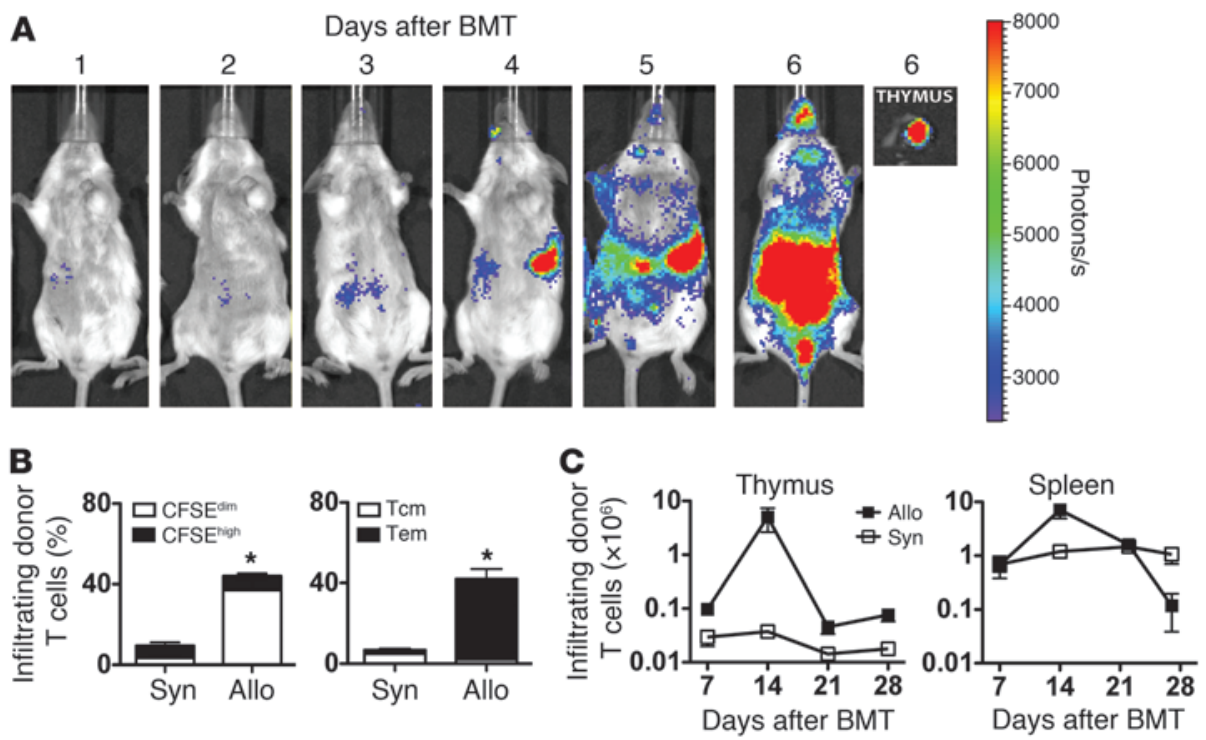

D
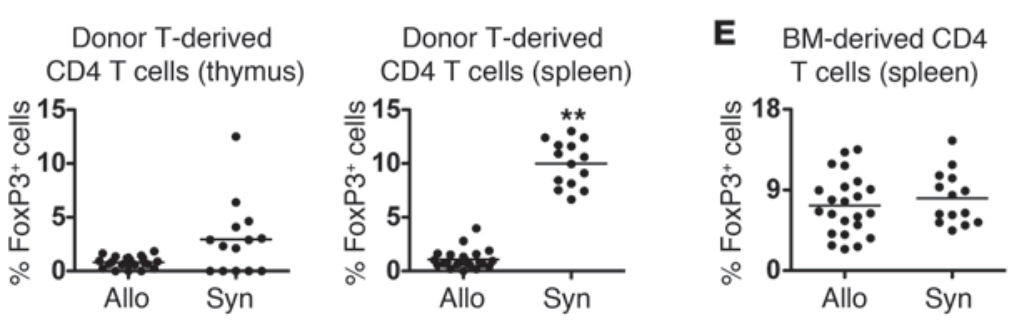

\section{Figure 2}

Alloreactive $T$ cells quickly infiltrate the thymus, undergo proliferation, and display an activated phenotype. (A) In vivo bioluminescence imaging (BLI) of alloreactive T cell $\left(0.25 \times 10^{6}\right)$ migration after transplant. Ex vivo imaging of the thymus confirmed donor T cell infiltration on day 6 . Representative images from 1 of 2 identical experiments are shown. (B) Percentages of proliferating alloreactive (CFSEdim) and nonproliferating (CFSE ${ }^{\text {hi }}$ ) infiltrating donor T cells as well as donor central memory $\left(\mathrm{Tcm}, \mathrm{CD} 44^{\mathrm{hi}} \mathrm{CD} 62 \mathrm{~L}^{\mathrm{hi}}\right)$ and effector memory $\left(\mathrm{Tem}, \mathrm{CD} 44^{\mathrm{hi}} \mathrm{CD} 62 \mathrm{~L}^{\mathrm{lo}}\right) \mathrm{T}$ cells as a fraction of all leukocytes (CD45+ cells). $n=14$ /group, combined from 2 identical experiments (mean \pm SEM). ${ }^{*} P<0.05$ allogeneic (allo) versus syngeneic (syn). (C) Infiltrating donor T cells in the thymus and spleen (mean \pm SEM) at days 7, 14, 21, and 28 in BALB/c (allogeneic) or B6 (syngeneic) recipients. $n=14-15 /$ group, combined data from 1 to 4 identical experiments (mean \pm SEM). (D) FoxP3 ${ }^{+} T$ cells derived from infused donor $\mathrm{T}$ cells are shown as a percentage of all donor-infused Thy $1.1^{+} \mathrm{CD} 4^{+}$ T cells in thymus and spleen at day 28 after allogeneic and syngeneic BMT. ${ }^{*} P<0.01$ allogeneic versus syngeneic groups. $n=14$, syngeneic; $n=18$, allogeneic; combined data from 3 identical experiments. (E) FoxP3 ${ }^{+} \mathrm{T}$ cells in the spleen, as derived from donor BM-derived $\mathrm{T}$ cells, are shown as a percentage of all donor BM-derived CD45.1 ${ }^{+} \mathrm{CD} 4{ }^{+} \mathrm{T}$ cells on day 28 after allogeneic and syngeneic BMT. $P=$ NS. $n=14$, syngeneic; $n=23$, allogeneic; combined data from 2 to 4 identical experiments. ( $\mathbf{D}$ and $\mathbf{E}$ ) Dots represent individual animals, and horizontal bars indicate the mean.

$1 \mathrm{H}$, left), similar to the normal thymus of a nontransplanted mouse. However, recipients of TCD-BM plus $0.25 \times 10^{6}$ B6 WT T cells (GVHD) had remarkable disruption of thymic architecture, including thinning of the cortex and loss of the corticomedullary junction (Figure $1 \mathrm{H}$, right).

To assess the sensitivity of the thymus and its architecture to damage during tGVHD at even lower doses of donor $\mathrm{T}$ cells in the allograft, we transplanted BALB/c mice (8.5 Gy) with TCD-BM with or without $0.5 \times 10^{5}$, $1 \times 10^{5}$, or $2.5 \times 10^{5} \mathrm{WT} \mathrm{T}$ cells and quantified thymic cortical and medullary areas on day 28 after transplant in these recipients to assess in particular the loss of the thymic cortex and the loss of the corticomedullary junction. Recipients of as few as $1 \times 10^{5}$ donor $\mathrm{T}$ cells exhibited a statistically significant loss of thymic cortical area (Figure 1I and Table 1) as well as a loss of the corticomedullary junction in some animals (Table 1). These results again demonstrate the exquisite sensitivity of the thymus to tGVHD, which manifested as derangements in thymic cytoarchitecture, with even small numbers of donor alloreactive $T$ cells.

We conclude from these experiments that small numbers of donor alloreactive $T$ cells cause dose-dependent thymic damage in allo-BMT recipients, which is associated with specific changes in thymic architecture and results in decreased export of $\mathrm{T}$ cells. Consequently, the thymus is exquisitely sensitive to GVHD.

Donor alloreactive $T$ cells rapidly infiltrate the thymus after allo-BMT and become profoundly activated. To assess the kinetics of donor alloreactive $\mathrm{T}$ cell infiltration of the thymus, we transplanted irradiated BALB/c mice with B6 TCD-BM and $0.25 \times 10^{6} \mathrm{~B} 6$ assessed thymic export and numbers of splenic RTEs (EGFP ${ }^{+}$ cells) on day 42 after transplant and noted that as few as $10^{5}$ donor FVB T cells were sufficient to cause a significant decrease in thymic export (Figure 1G). Furthermore, this effect was dosedependent, such that increasing numbers of donor FVB T cells in the allograft caused a corresponding decrease in RTE numbers (Figure $1 G$ ). Similar results were observed in an experiment using irradiated BALB/c recipients (data not shown). This suggests that increasing donor $\mathrm{T}$ cell numbers and tGVHD severity negatively impacts thymic function.

Finally, we assessed thymic architecture in allo-BMT recipients with GVHD. Recipients of TCD-BM only (no GVHD) had a thymic architecture with well-defined cortical and medullary areas (Figure luciferase ${ }^{+} \mathrm{T}$ cells, then tracked their migration and expansion with daily bioluminescent imaging studies. At this $\mathrm{T}$ cell dose, we began to detect a signal in the thymus by days 5 to 6 after transplant (Figure 2A). Additionally, in parallel allo-BMT experiments with a doses of $0.5 \times 10^{6}, 1 \times 10^{6}$, or $10 \times 10^{6} \mathrm{~B} 6$ luciferase $^{+}$ $\mathrm{T}$ cells, we were able to detect cells in the thymus as early as days 2 or 3 after transplant (Supplemental Figure 5), suggesting that a small percentage of donor alloreactive $T$ cells traffic to the thymus with rapid kinetics.

To further characterize thymus-infiltrating T cells, we transferred CFSE-labeled purified B6 CD45.1 splenic T cells into irradiated syngeneic $(\mathrm{B} 6,11 \mathrm{~Gy})$ or allogeneic (BALB/c, $8.5 \mathrm{~Gy}$ ) recipients. On day 6 after adoptive transfer, we observed that donor $\mathrm{T}$ cells 
A

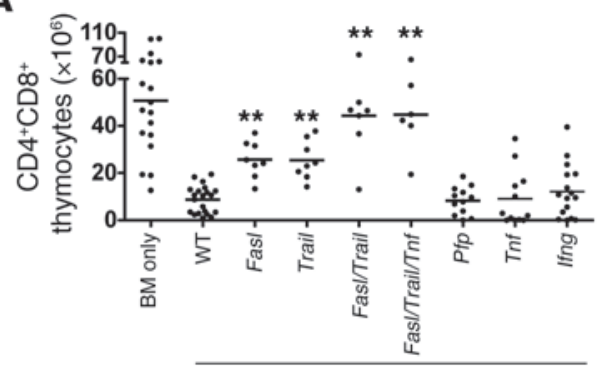

Deficient - donor T cells

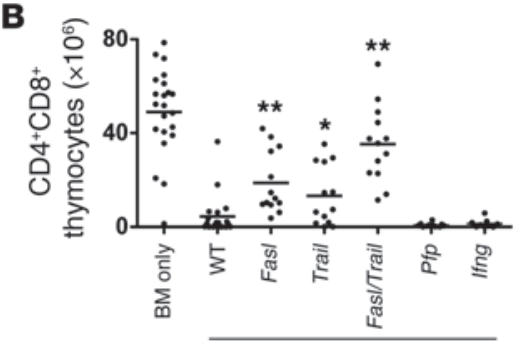

Deficient - donor T cells
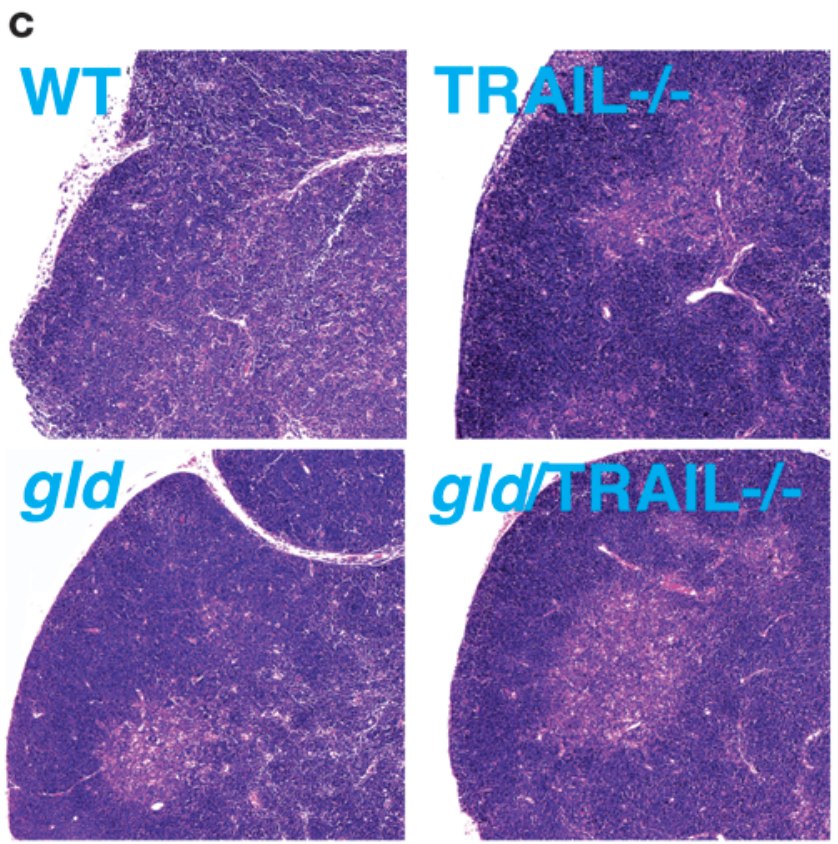

D

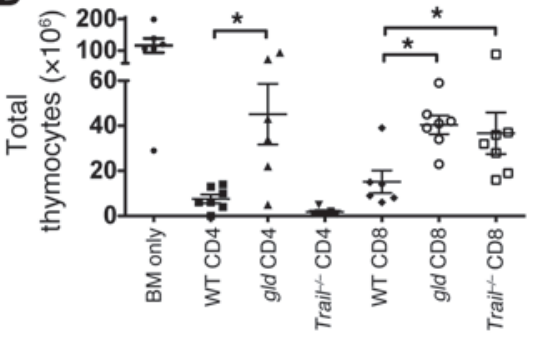

E

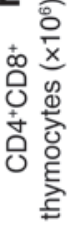

.

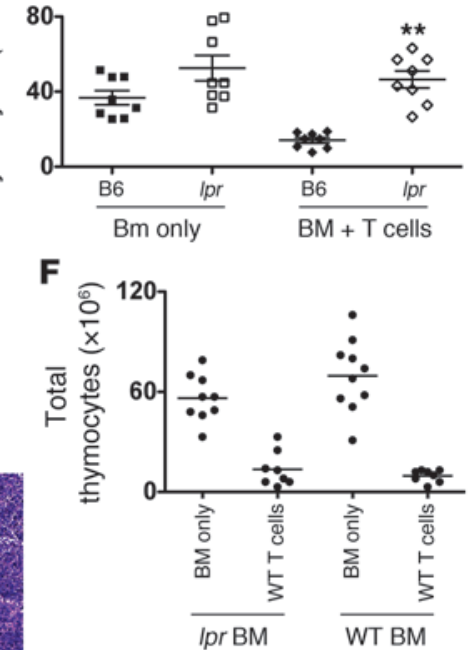

Figure 3

Alloreactive T cells require FasL and TRAIL to mediate tGVHD. (A) BM-derived CD4+CD8 $(\mathrm{DP})$ thymocytes in recipients of B6 CD45.1 TCD-BM with or without $0.25 \times 10^{6} \mathrm{~B} 6$ versus B6.KO (deficient for cytolytic molecules) donor T cells on day 28. BM only, $n=18$; WT T cells, $n=21$; gld (FasL deficient),

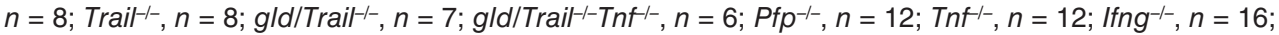
combined data from 2 independent experiments. (B) Experiment as in A with $0.5 \times 10^{6}$ donor T cells. BM

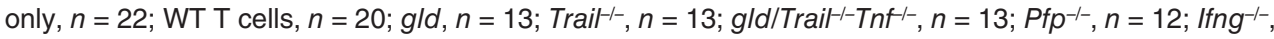
$n=9$; combined data from 2 to 3 independent experiments. (A and $\mathbf{B}$ ) ${ }^{\star} P<0.05,{ }^{*} P<0.01$ versus WT. (C) Thymic architecture of thymus sections from A were analyzed (H\&E, day 28). Representative sections are shown. Original magnification, $\times 50 . n=5 /$ group. (D) Total thymocyte counts in mice that received B6 BM with or without $0.25 \times 10^{6}$ CD5+ B6 WT CD4, WT CD8, Trail-l- CD4, Trail-/- CD8, gld CD4, or gld CD8 T cells. Symbols represent individual animals (mean \pm SEM). ${ }^{*} P<0.05 . n=6-7 / g r o u p$. (E) Absolute numbers of BM-derived CD45.1 ${ }^{+} \mathrm{CD} 4{ }^{+} \mathrm{CD} 8{ }^{+}$thymocytes in $/ p r$ (Fas receptor deficient) and WT B6 recipients on day 28. Symbols represent individual animals (mean \pm SEM). $n=8$ /group. ${ }^{* *} P<0.01$ versus corresponding WT controls. (F) Total thymocytes in recipients of Ipr or WT B6 TCD-BM and T cells on day 28. Dots represent individual animals. Horizontal bars indicate the mean (A, B, and F). $n=8-10 /$ group.

comprised a significantly greater proportion of $\mathrm{CD}^{4} 5^{+}$hematopoietic cells in the thymus of allogeneic recipients as compared with syngeneic recipients and that the majority of donor $\mathrm{T}$ cells in allogeneic recipients were CFSE dim, indicating rapid proliferation and alloactivation (Figure 2B, left). In addition, the majority of donor $\mathrm{T}$ cells in the thymi of allo-BMT recipients were $\mathrm{CD} 44^{\mathrm{hi}} \mathrm{CD} 62 \mathrm{~L}^{\text {lo }}$, indicating a effector memory $\mathrm{T}$ cell phenotype, with a minority of $\mathrm{CD} 44^{\text {hi }} \mathrm{CD} 62 \mathrm{~L}^{\text {hi }}$ central memory cells (Figure 2B, right). We conclude that alloactivated and proliferating donor $\mathrm{T}$ cells with an effector memory $\mathrm{T}$ cell phenotype infiltrate the thymus early after allo-BMT.

Donor alloreactive $T$ cells have a characteristic peak at day 14 after transplant. To assess the longerterm kinetics of $\mathrm{T}$ cell infiltration during tGVHD, we transplanted $\mathrm{B} 6$ and $\mathrm{BALB} / \mathrm{c}$ mice with $\mathrm{B} 6$ Thy1.1 splenic $\mathrm{T}$ cells and $\mathrm{B} 6$ CD45.1 ${ }^{+}$TCD-BM. We observed a peak in donor alloactivated Thy $1.1^{+} \mathrm{T}$ cells in the thymus on day 14 after allo-BMT, with a subsequent decline and low but sustained numbers at day 21 and day 28 after transplant (Figure 2C). We observed similar kinetics in the spleen, although there the decline in Thy $1.1^{+}$donor $\mathrm{T}$ cell numbers from day 14 to day 28 was more gradual (Figure 2C).

Donor alloreactive $\mathrm{T}$ cellderived Tregs are dramatically decreased in the spleens but not thymi of allogeneic versus syngeneic BMT recipients. Tregs of donor and host origin have been demonstrated as important negative regulators of GVHD (26, 27). We therefore assessed donor FoxP3 ${ }^{+}$Tregs as a percentage of donor infused CD4 $\mathrm{T}$ cells in the spleens and thymi of BMT recipients. While the percentages of donor Tregs derived from the infused $\mathrm{T}$ cells were significantly reduced in the spleen of alloBMT recipients versus syngeneic BMT recipients, the fraction of Tregs derived from the infused $\mathrm{T}$ cells in the thymi of allo-BMT 
Treatment days $-1,1,3,5$
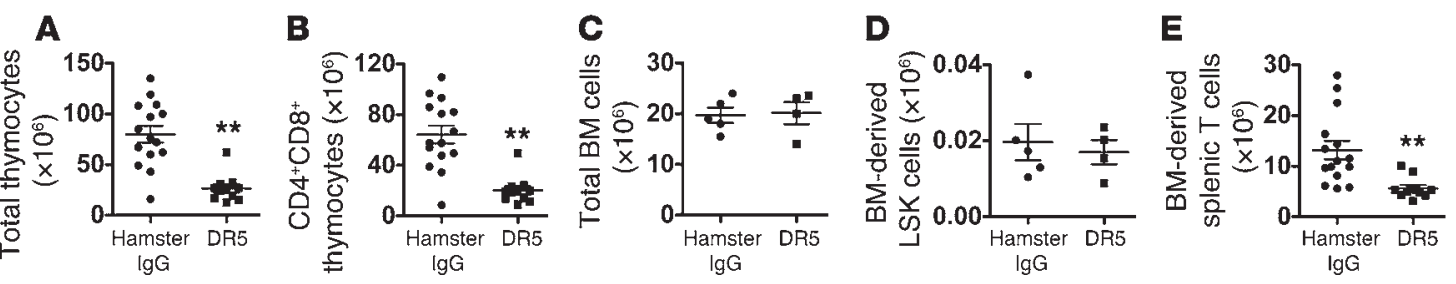

Treatment days $10,12,14,16$
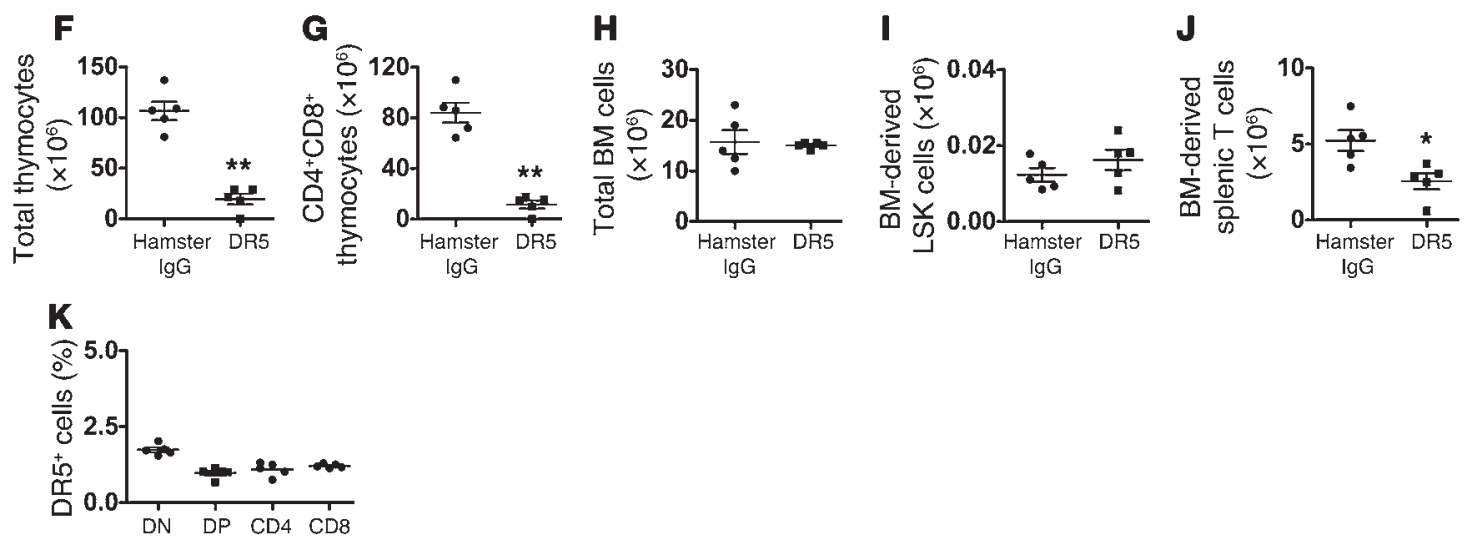

\section{Figure 4}

Soluble DR5 agonists are sufficient to damage the thymus after allo-BMT in 5×106 B6 CD45.1 + TCD-BM only $\rightarrow$ BALB/c (8.5 Gy) mice. Recipients were treated with $200 \mu \mathrm{g}$ hamster IgG control antibody or DR5-1 agonistic antibody i.p. on days -1, 1, 3, and 5 peritransplant (A-E) or on days 10,12, 14, and 16 after transplant $(\mathbf{F}-\mathbf{J})$. Recipients were analyzed at day 28 after transplant. Symbols represent individual animals (mean \pm SEM). ${ }^{*} P<0.05,{ }^{\star \star} P<0.01$ versus hamster IgG; combined data from 2 independent experiments. (A) Total thymocytes and (B) donor BM-derived CD45.1 ${ }^{+}$CD4 ${ }^{+}$CD8 ${ }^{+}$(DP) thymocytes. DR5-1, $n=11$; hamster IgG, $n=15$. (C) Total BM cells. $n=4-5 / g r o u p$. (D) Donor LSK cells from the BM. $n=4-5 /$ group. (E) Donor splenic CD45.1 ${ }^{+}$CD $3 \varepsilon^{+}$T cells. DR5-1, $n=11$; hamster IgG, $n=15$. (F) Total thymocytes and $(\mathbf{G})$ donor BM-derived CD45.1 ${ }^{+}$CD4 ${ }^{+}$CD8 ${ }^{+}$(DP) thymocytes. DR5-1, $n=5 /$ group. (H) Total BM cells. $n=5 /$ group. (I) Donor LSK cells from the BM. $n=5 /$ group. (J) Donor splenic CD45.1 ${ }^{+} \mathrm{CD} 3 \varepsilon^{+} \mathrm{T}$ cells. $n=5$ /group. $(\mathbf{K})$ Mice were transplanted as above. Thymi from recipients of hamster IgG control antibody only were harvested at day 28, stained with anti-DR5 antibody, and gated for donor CD45.1+ thymocytes subsets (CD4-CD8-, $\mathrm{CD}^{+}{ }^{+} \mathrm{CD} 8{ }^{+}, \mathrm{CD}^{+}{ }^{+} \mathrm{CD} 8-$, and CD4-CD8 $)$ as shown. The percentage of cells that are DR5 positive was determined based on an isotype control gate set at less than $0.25 \%$ positive. $n=5$ /group. Horizontal bars indicates the mean. $D N, C D 4^{+} C D 8^{+}$double negative.

recipients with GVHD versus syngeneic recipients was not significantly different (Figure 2D).

We also assessed the influence of tGVHD on the numbers of donor BM-derived Tregs in the spleen on day 28 after transplant. We observed similar percentages of donor $\mathrm{CD} 45.1^{+} \mathrm{CD} 4^{+} \mathrm{FoxP} 3^{+}$Tregs as a percentage of donor $\mathrm{BM}$-derived $\mathrm{CD} 45.1^{+} \mathrm{CD} 4^{+}$donor $\mathrm{T}$ cells in recipients of syngeneic and allogeneic BMT (Figure 2E). We interpret these data to signify that $\mathrm{GVHD}$ does not disproportionately impact the reconstitution of donor BM-derived Tregs in the periphery.

Donor alloreactive Tcells require FasL and TNF-related apoptosis-inducing ligand to mediate $t G V H D$. Next, we assessed the T cell cytolytic molecules and pathways required for $\mathrm{tGVHD}$. Comparing numbers of donor BM-derived thymocytes on day 28 in recipients of WT B6 versus recipients of B6.KO (deficient for cytolytic molecule) donor $\mathrm{T}$ cells, we observed that FasL and TNF-related apoptosis-inducing ligand (TRAIL) were both required for $\mathrm{TGVHD}$, while TNF and perforin $(P f p)$ were dispensable (Figure 3A). This agrees with our previous finding that alloactivated $T$ cells can express FasL and TRAIL $(28,29)$. Interestingly, we also observed that donor T cellderived IFN- $\gamma$ was dispensable for tGVHD (Figure 3A).

Since recipients of generalized lymphoproliferative disease ( $g l d$, also known as Fasl) and Trail ${ }^{-}$-T cells demonstrated significant increases in donor $\mathrm{BM}$-derived $\mathrm{CD} 45.1^{+} \mathrm{CD} 4^{+} \mathrm{CD} 8{ }^{+}$thymocytes, we asked whether interference with both these cytolytic pathways could further attenuate $\mathrm{tGVHD}$. We therefore generated mice which were either deficient for both FasL and TRAIL ( $\mathrm{gld} /$ Trail $^{--}$) or mice additionally deficient for TNF ( $\mathrm{gld} / \mathrm{Trail}^{-/} \mathrm{Tnf}^{-}$). . Donor T cells from both of these mice were ineffective at mediating tGVHD (Figure 3A) or systemic GVHD (data not shown), and $\mathrm{CD} 4^{+} \mathrm{CD} 8{ }^{+}$thymocyte numbers on day 28 were similar to that of allo-BMT recipients of TCD-BM only (no GVHD). These results suggest that FasL and TRAIL are primary effector pathways by which donor alloreactive $T$ cells damage the thymus.

We also assessed the requirements for tGVHD at higher doses of donor T cells (B6 $\rightarrow$ BALB $/ c$ with $0.5 \times 10^{6} \mathrm{~T}$ cells) and again confirmed that, even in this setting, the FasL and TRAIL pathways are required to mediate $\mathrm{tGVHD}$, while the perforin and IFN- $\gamma$ pathways were dispensable (Figure 3B). Moreover, recipients of gld/Trail ${ }^{--}$doubly deficient donor $\mathrm{T}$ cells exhibited additionally increased numbers of donor $\mathrm{CD} 45.1^{+} \mathrm{CD} 4^{+} \mathrm{CD} 8^{+}$thymocytes as compared with recipients of $\mathrm{Trail}^{-/}$or gld singly deficient donor T cells $(P<0.05)$, suggesting a nonredundant role for these 2 pathways at this higher $T$ cell dose (Figure $3 \mathrm{~B}$ ).

We further assessed the influence of donor alloreactive $T$ cell FasL and TRAIL on thymic architecture and observed that while 
A
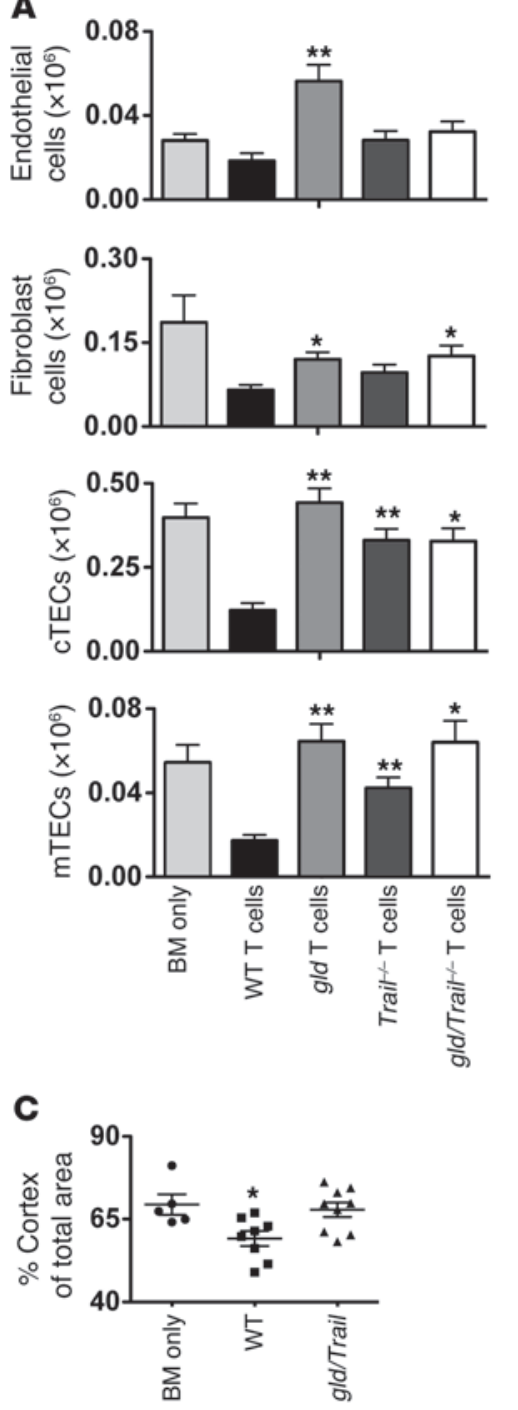

B
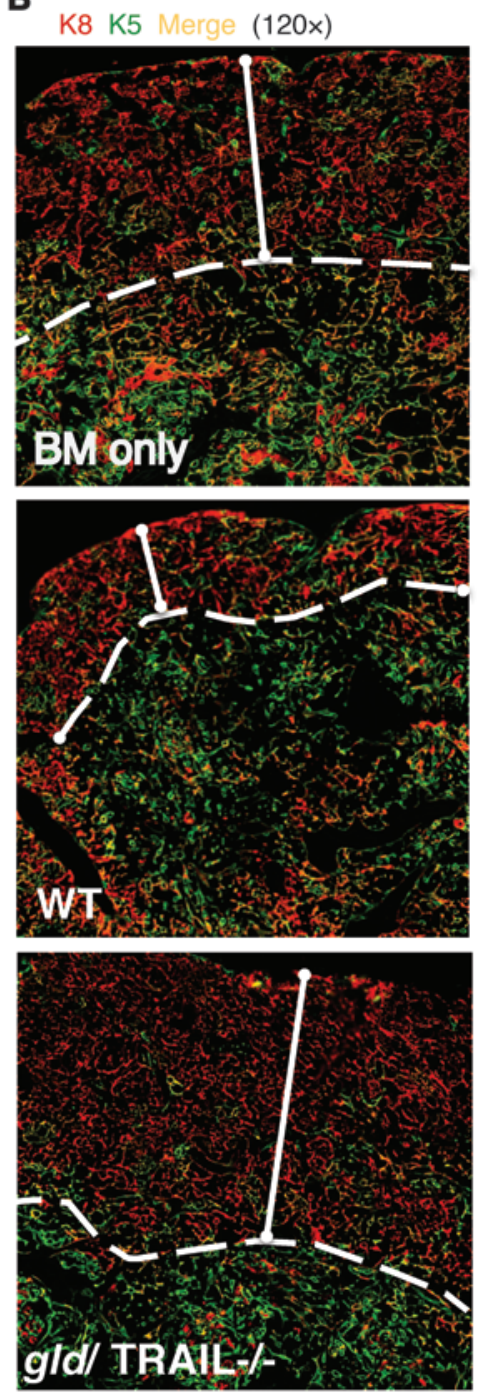

\section{Figure 5}

tGVHD causes damage to the thymic stroma, loss of thymic epithelial cells, and cortical thinning. (A) CD45- thymic stromal cell subsets were assessed by flow cytometry in allo-BMT recipients of TCD-BM with or without WT, Trail-/-, gld, or gld/Trail-1- T cells. Absolute numbers are displayed (mean \pm SEM). TCD-

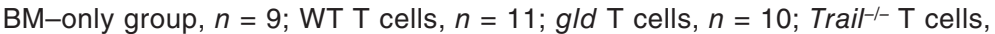
$n=12 ;$ gld $/$ Trail $^{-/-}$T cells, $n=5$. Combined data from 2 identical experiments. Endothelial cells, CD45-CD31+MHC class IIdim; fibroblasts, CD45-PDGFR1+MHC class IIneg; cTECs, CD45-CD31-MHC class IInt/hiUEA-1-; mTECs, CD45-CD31MHC class II int/hiUEA-1+. ${ }^{*} P<0.05,{ }^{* *} P<0.01$ versus WT T cells. (B) Representative paraffin-fixed thymus sections from the groups that received TCD-BM with or without $0.25 \times 10^{6} \mathrm{WT}$, Trail-l- , gld, or gld/Trail-l- T cells were stained for K8-positive (red) cortical and K5-positive (green) medullary regions and analyzed by confocal microscopy at day 28 after transplant. Dotted lines indicate the corticomedullary junction. Solid lines indicate cortical thickness. Original magnification, $\times 120$. Representative images are shown ( $n=2-3$ /group). (C) Experiment was performed as in $\mathbf{B}$. Three paraffin-fixed thymus sections per thymus, spaced $50 \mu \mathrm{m}$ apart in each organ, were stained with K5 and K8 antibody and analyzed by confocal microscopy to quantitatively analyze total, medullary, and cortical areas. Averaged percent cortical area (mean \pm SEM) was then determined as a fraction of total area. Symbols indicate individual animals. BM-only group, $n=5$; WT and $\mathrm{gld} /$ Trail/-- $^{-}$groups; $n=8-9$; combined data from 2 identical experiments. ${ }^{*} P<0.05$ versus $\mathrm{BM}$ only.

allo-BMT recipients of WT T cells had complete loss of distinction between the thymic cortical and medullary zones, recipients of Trail-/-, gld, and gld/Trail-/- $\mathrm{T}$ cells had intact thymic microarchitecture (Figure 3C).

Both CD4 and CD8 cells require FasL to mediate $t G V H D$, but $T R A I L$ is only required for CD8 T cells to mediate $t G V H D$. We further studied the importance of FasL and TRAIL on donor $\mathrm{CD}^{+}$and $\mathrm{CD}^{+}$alloreactive $\mathrm{T}$ cells and performed transplants with $0.25 \times 10^{6}$ purified WT, gld, or Trail-/donor CD4 or CD8 T cells. These experiments revealed that FasL is important on both CD4 and CD8 alloreactive T cells for mediating tGVHD, whereas TRAIL is only important on donor CD8 T cells (Figure 3D).

Donor alloreactive $T$ cells damage host-derived thymic stroma via the FasL pathway to cause $t G V H D$. To study whether donor alloreactive T cells mediated tGVHD against donor (syngeneic) BM-derived thymocytes or host tissues, we transplanted WT or $l p r$ (Fas receptordeficient) B6 mice with BALB/c TCD-BM and T cells and measured donor thymic cellularity on day 28 after transplant. These experiments revealed that while WT and $l p r$ recipients of TCD-BM only had similar thymic cellularity, Ipr recipients of T cell-replete allo-BMT had significantly increased numbers of donor BM-derived $\mathrm{CD}^{+} \mathrm{CD}^{+}$thymocytes as compared with WT recipients, indicating that $l p r$ allo-BMT recipients were resistant to tGVHD (Figure 3E). These results suggest that expression of the Fas receptor on host-derived thymic stroma is required for tGVHD.

In contrast, experiments in which we transplanted $\mathrm{BALB} / \mathrm{c}$ mice with lpr BM versus those in which we transplanted BALB/c mice with B6 BM with or without WT $T$ revealed no significant differences, indicating that Fas receptor on donor BM-derived thymocytes is not directly involved in sensitivity to tGVHD (Figure 3F).

Soluble DR5 agonists are sufficient to damage the thymus after TCD allo-BMT. We further studied the role of TRAIL in mediating thymic damage after transplant by administering anti-mDR5-1 agonistic antibody to recipients of TCD allo-BMT, which did not receive any donor alloreactive $\mathrm{T}$ cells. The administration of a soluble TRAIL analog in this setting allowed us to clarify several aspects of TRAIL biology, which include the requirement for GVHD-associated inflammatory cytokines to enable TRAIL-mediated thymic damage in recipients of TCD allo-BMT and the requirement for other alloreactive $\mathrm{T}$ cell-mediated cytolytic pathways to enable TRAIL-mediated damage. Furthermore, we performed experiments in which we treated mice with anti-mouse DR5-1 agonistic antibody both immediately after transplant or with a delay in administration, which allowed us to probe the temporal sensitivity of the thymus to TRAIL/DR5-mediated killing.

In experiments in which we administered DR5-1 agonistic antibody "early," during the peritransplant period (200 $\mu$ g i.p. days $-1,1,3,5)$, and analyzed recipients on day 28 after transplant, we observed a highly significant decrease in total thymocyte numbers (Figure 4A) as well as donor $\mathrm{CD} 45.1^{+} \mathrm{CD} 4^{+} \mathrm{CD} 8^{+}(\mathrm{DP})$ thymocyte numbers (Figure 4B) in recipients of this antibody as compared 
A
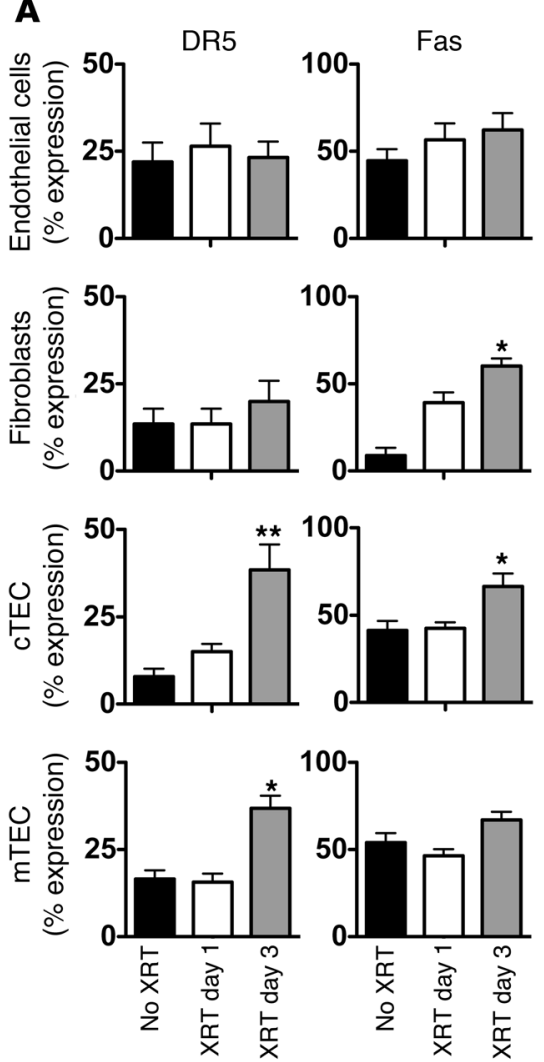

B
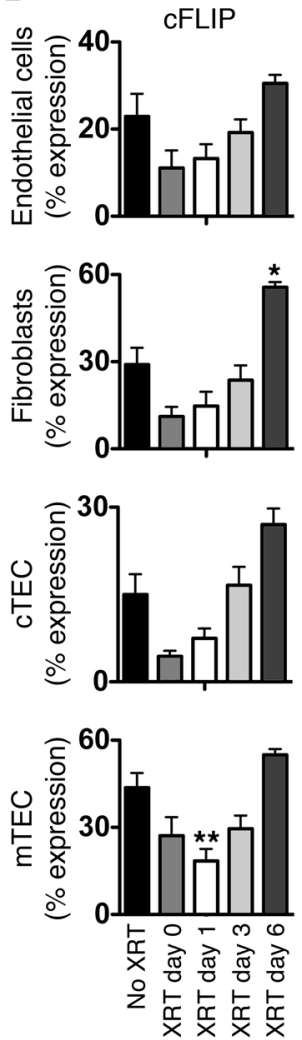

with recipients of hamster IgG control. We also analyzed the BM of recipients and found comparable total numbers of BM cells and early donor precursors $\left(\mathrm{CD} 45.1^{+}\right.$lineage $-\mathrm{Sca}-1^{+} \mathrm{c}-\mathrm{Kit}^{+}[\mathrm{LSK}]$ cells) in recipients of DR5-1 versus hamster IgG (Figure 4, C and D), suggesting that DR5-1 treatment did not directly influence the BM compartment. In addition, we found that recipients of DR5-1 had significantly decreased numbers of BM-derived T cells (Figure 4E), suggesting that DR5-1 antibody treatment impairs thymic output.

Next, to address the temporal sensitivity and effects of conditioning-regimen associated inflammation (e.g., cytokines) on the TRAIL-mediated thymic damage, we administered DR5-1 antibody or hamster IgG control (200 $\mu$ g i.p.) on days 10, 12, 14, and 16 after transplant. On day 28 , we again observed a decrease in total thymocyte numbers (Figure $4 \mathrm{~F}$ ) and donor $\mathrm{CD} 45.1^{+} \mathrm{CD} 4^{+} \mathrm{CD} 8^{+}$thymocyte numbers (Figure 4G) but no effect on total BM and donor LSK cellularity (Figure 4, H and I). Donor T cells in the spleen were again decreased in recipients of DR5-1 antibody (Figure 4J). These data suggest that conditioning-associated inflammation is not required for TRAIL/DR5-mediated thymic damage. Finally, we noted that donor CD 45.1 $1^{+}$thymocytes expressed low levels of DR5, suggesting that DR5-1 does not directly act on donor thymocytes (Figure 4K).

Together, these experiments indicate that the thymus is sensitive to TRAIL/DR5-mediated damage after allo-BMT, in the absence of donor alloreactive $\mathrm{T}$ cells, their other cytolytic pathways, or the inflammatory cytokines associated with donor alloactivated $\mathrm{T}$ cells, the conditioning regimen, and GVHD. Additionally, the thymus appears to be sensitive to TRAIL/DR5-mediated damage throughout at least the early period of reconstitution (days 10-16).

Donor alloreactive $T$ cells damage thymic medullary and cortical epithelium as well as thymic endothelium and fibroblasts. Thymic stroma

\section{Figure 6}

Thymic stromal cells upregulate the death receptors Fas and DR5 and downregulate the antiapoptotic protein cFLIP, upon exposure to radiation. Nontransplanted BALB/c mice were lethally irradiated (XRT) (8.5 Gy), and CD45- thymic stromal cell subsets were analyzed for Fas and DR5 on days 1 and $3(\mathbf{A})$ and intracellular cFLIP expression on days $0,1,3$, and 6 (B) by flow cytometry. On day 0 , mice were analyzed 4-6 hours after exposure (mean \pm SEM). Nonirradiated BALB/c mice served as controls. ${ }^{*} P<0.05$, ${ }^{* *} P<0.001$ versus control; combined data from 2-3 identical experiments. Gating for percentage of expression was based on isotype controls, with limits set at $2 \% . n=5-13$ / group for DR5 and Fas expression; $n=15-17$ /group for cFLIP expression; combined results from 2 to 3 identical experiments.

is a heterogenous population consisting of nonhematopoietic cells such as endothelium and cortical and medullary thymic epithelial cells (cTECs and mTECs) as well as fibroblasts. DCs and macrophages constitute the hematopoietic component of thymic stroma. As we were interested in host thymic stroma, we focused on nonhematopoietic cells and asked which populations were susceptible to tGVHD and damage by donor alloreactive $T$ cells.

Upon digesting the thymi of allo-BMT recipients of TCD-BM with or without WT, gld, Trail/-, and gld/Trail $/-\mathrm{T}$ cells, we were surprised to note that all nonhematopoietic stromal cells, including endothelium, fibroblasts, cTECs, and mTECs, were increased in recipients of gld as compared with those of WT donor $\mathrm{T}$ cells (Figure 5A). Furthermore, recipients of Trail ${ }^{--} \mathrm{T}$ cells showed increased numbers of MTECs and cTECs but not fibroblasts and endothelium (Figure 5A). Recipients of gld/Trail $/-\mathrm{T}$ cells had a phenotype similar to that of recipients of gld $\mathrm{T}$ cells. These observations suggested to us that donor alloreactive $T$ cells use TRAIL to cause damage to mTECs and cTECs, whereas FasL is required for damage to all stromal cell subsets.

Donor alloreactive $T$ cells and $t G V H D$ cause cortical thinning in the thymus via the FasL and TRAIL pathways. We further studied damage to the thymic stroma and thymic microarchitecture by staining sections from recipients of TCD-BM with or without WT T or gld/Trail/- donor T cells. Analysis with the thymic cortical marker cytokeratin 8 (K8) and thymic medullary marker keratin 5 (K5) revealed that WT donor alloreactive $\mathrm{T}$ caused $\mathrm{tGVHD}$ and cortical thinning, whereas gld/Trail/- donor alloreactive $\mathrm{T}$ cell did not (Figure 5B). In addition, a systemic quantitative analysis of cortical and medullary areas in recipients of $\mathrm{T}$ cell-depleted and $\mathrm{T}$ cell-replete allo-BMT revealed that recipients of WT T cells had a statistically significant loss of cortical area $(P<0.05)$ as compared with recipients of TCD-BM alone, whereas recipients of gld $/$ Trail $^{-/} \mathrm{T}$ cells had similar thymic cortical area as recipients of TCD-BM only (Figure 5C). These observations further suggest that FasL and TRAIL are important for cortical thinning, a hallmark feature of tGVHD.

Thymic stromal cells upregulate Fas and DR5 and downregulate caspase-8-like inhibitory protein upon exposure to radiation. Radiation both directly induces cellular apoptosis and sensitizes cells to other apoptotic stimuli. As radiation is an important part of many allo-BMT-conditioning regimens, we hypothesized that irradiation of the thymic stroma could be important for its sensitization to tGVHD and the death ligands FasL and TRAIL. We therefore irradiated nontransplanted BALB/c mice, and, in thymic stromal cells, we measured their cell-surface expression of Fas and DR5, which are receptors for FasL and TRAIL, respectively, as well as their expression of the intracellular protein caspase-8-like inhibi- 

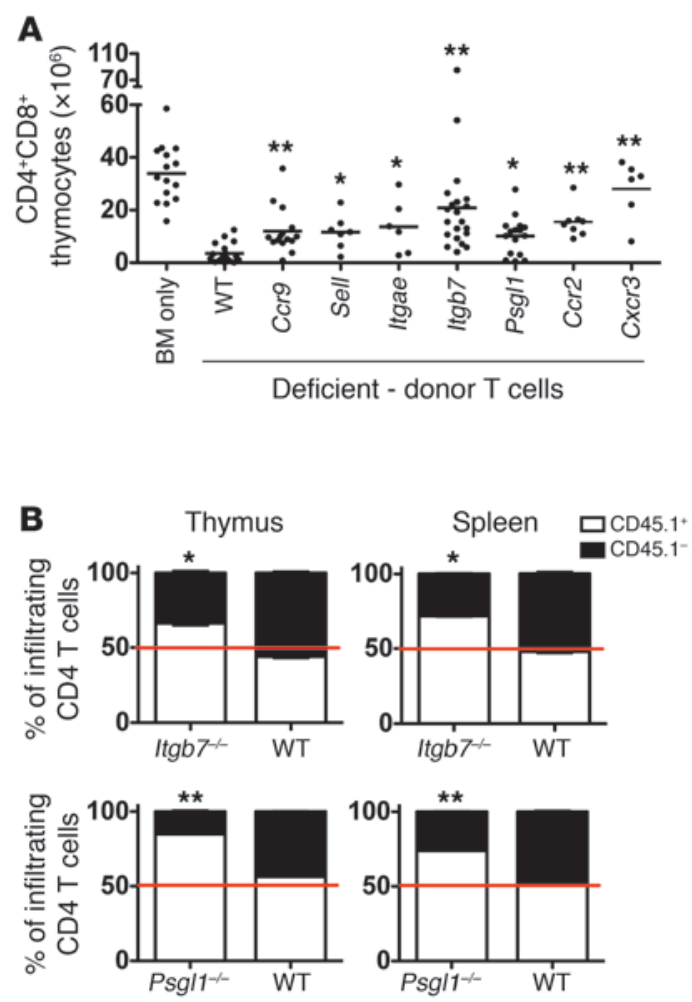

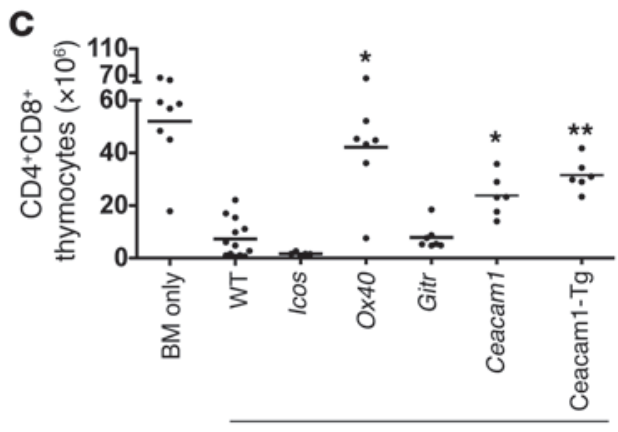

Deficient - donor T cells

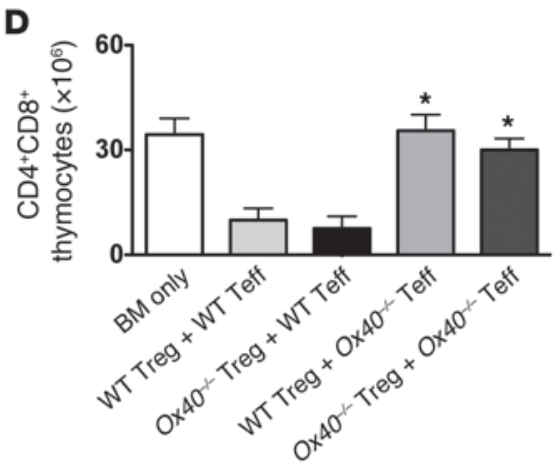

Figure 7

Alloreactive T cells require various homing molecules and costimulatory/inhibitory molecules to mediate tGVHD. (A) Allo-BMT and analysis was done as in Figure 3A. Dots represent individual animals. ${ }^{*} P<0.05,{ }^{* *} P<0.001$ versus WT. BM only, $n=15$; WT T cells, $n=17$; Ccr9 ${ }^{-/-}, n=15$;

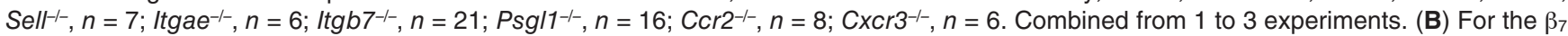

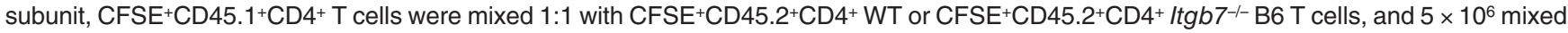
cells were transferred into irradiated BALB/c. Infiltrating donor T cells on day 7 are shown. $n=5 /$ group. For PSGL-1, CD45. $1^{+}$CFSE B6 T were mixed 1:1 with $\mathrm{CFSE}+\mathrm{CD} 45.2^{+}$WT T or $\mathrm{CFSE}{ }^{+} \mathrm{CD} 45.2 P$ sgl1-- $\mathrm{B} 6 \mathrm{~T}$ cells and adoptively transferred. Recovered CD4 ${ }^{+} \mathrm{T}$ cells are shown. $n=10 /$ group (mean $\pm \mathrm{SEM}$ ). ${ }^{*} P<0.05,{ }^{*} P<0.001$ for percentage of CD45.1- B6.KO versus B6.WT T cells. (C) Allo-BMT and analysis was done as in Figure 3A. Squares represent individual animals. ${ }^{\star} P<0.05$, ${ }^{\star \star} P<0.001$ versus WT. BM only, $n=8$; WT T cells, $n=13$; Icos ${ }^{-1-}, n=5$; Ox40-1-, $n=7$; Gitr ${ }^{--}, n=7$; Ceacam1--- $n=6$; Ceacam1-Tg, $n=6$; combined from 1 to 2 experiments. (D) Numbers of BM-derived CD45.1+CD4+CD8+ (DP) thymocytes (mean \pm SEM) in recipients of $5 \times 10^{6} \mathrm{~B} 6 \mathrm{CD} 45.1 \mathrm{TCD}-\mathrm{BM}$ with or without $3.2 \times 10^{6}$ Teffs plus $0.8 \times 10^{6}$ Tregs. ${ }^{*} P<0.05$ versus WT Tregs plus WT Teffs; recipients of TCD-BM only and recipients of Ox40-/- Tregs plus WT B6 Teffs, $n=5$; all other groups, $n=7 /$ group. Horizontal bars indicate the mean.

tory protein (cFLIP), a negative regulator of Fas-mediated and DR5-mediated apoptosis.

These experiments revealed that cTECs and mTECs significantly upregulate DR5 by day 3 after irradiation and that thymic fibroblasts and cTECs upregulate Fas by day 3 after irradiation (Figure $6 \mathrm{~A})$. Furthermore, there is a transient decrease in cFLIP levels on day 1 after irradiation in mTECs and a similar trend in cTECs, fibroblasts, and endothelium (Figure 6B). This suggests that radiation injury indeed sensitizes thymic stromal cells to apoptosis via the FasL and TRAIL pathways.

Both canonical T cell thymus-trafficking molecules and T cell gut-trafficking molecules are implicated in $t G V H D$. A number of T cell-trafficking molecules have been implicated in GVHD. We assessed a subset of these molecules, including CCR9, L selectin, $\alpha_{\mathrm{E}}$ and $\beta_{7}$ integrin subunits, $\mathrm{P}$ selectin glycoprotein ligand-1 (PSGL-1), CCR2, and CXCR3, to evaluate their roles in mediating tGVHD. We performed experiments with B6.WT versus B6.KO (deficient for trafficking molecule) donor T cells, by transplanting B6.CD45.1 ${ }^{+}$ TCD-BM into lethally irradiated $\mathrm{BALB} / \mathrm{c}$ recipients $(8.5 \mathrm{~Gy})$ and assessing donor BM-derived $\mathrm{CD} 45.1^{+} \mathrm{CD} 4^{+} \mathrm{CD}^{+}$thymocyte numbers on day 28 after transplant (Figure 7A).

Recipients of donor alloreactive $\mathrm{T}$ cells deficient for molecules with documented functions in trafficking to the thymus (CCR9, L selectin, and PSGL-1; refs. 30-34) accordingly exhibited increased numbers of BM-derived CD $45.1^{+} \mathrm{CD} 4^{+} \mathrm{CD}^{+}$thymocytes as compared with recipients of WT T cells, indicating a partial rescue of tGVHD (Figure 7A). However, to our surprise, alloreactive $\mathrm{T}$ cells deficient for trafficking molecules traditionally ascribed to gut trafficking ( $\alpha_{\mathrm{E}}$ and $\beta_{7}$ integrin subunits, CCR2, CXCR3; refs. 35-38) also mediated attenuated tGVHD (Figure 7A). We note however, that no deficiency in any single trafficking molecule tested was sufficient to completely abrogate the ability of donor alloreactive $T$ cells to mediate $t G V H D$. This suggests both redundancy in the trafficking of donor alloreactive $T$ cells to the thymus, and that many of the molecules we tested are partially but not completely required for thymic homing (Figure 7A).

WT CD4 T cells out-compete Itgb7-1- and Psgl1 ${ }^{-1-}$ CD4 T cells in early trafficking to spleen and thymus. To distinguish whether the decrease 
in $\mathrm{tGVHD}$ was due to a specific, direct trafficking defect of $\left(\beta_{7}\right)$ Itg $b 7^{-/-}$donor $\mathrm{T}$ cells versus an indirect overall decrease in alloactivation of $\operatorname{tg} b 7^{-1-}$ donor $\mathrm{T}$ cells, we performed mixing experiments with $\operatorname{Itg} b 7^{-1-}$ and WT donor T cells. We combined purified CD4 T cells of WT B6 (CD45.1) origin with either $\operatorname{Itg}^{-1} 7^{--}$(CD45.2) CD4 $\mathrm{T}$ cells or WT (CD45.2) T cells in a 1:1 ratio. Upon infusing CFSE-labeled cell mixtures into irradiated BALB/c mice and analyzing the spleens and thymus on day 6 after adoptive transfer, we noted similar proliferation kinetics (data not shown) but increased numbers of WT CD4 T cells in both the spleen and thymus of recipients of WT CD $45.1^{+} /$Itgb7 $7^{-/-} \mathrm{CD} 45.2^{+}$mixtures (Figure 7B, top). Results of experiments performed with mixed CD8 T cells suggested that $\beta_{7}$ integrin was not important for CD8 T cell trafficking (Supplemental Figure 6A). The observation that WT CD4 $\mathrm{T}$ cells out-compete Itgb7-1- T cells in both spleen and thymus suggests that the $\beta_{7}$ integrin subunit may be involved in trafficking of alloreactive donor $T$ cells to the spleen and thymus. Similar experiments, in which whole WT versus $P s g l 1^{-/}$donor T cells were mixed, revealed also that WT T cells out-competed Psgl1-/- T cells in the spleen and thymus (Figure 7B, bottom, and Supplemental Figure $6 \mathrm{~B})$, suggesting that PSGL-1 may have indirect effects in mediating tGVHD, despite its requirement for early thymic progenitors from the BM to seed the thymus (33).

Ox40 and carcinoembryonic antigen-associated cell adhesion molecule 1 regulate the activation of alloreactive donor $T$ cells during $t G V H D$. We assessed a variety of costimulatory and coinhibitory molecules important for alloreactive T cell function during GVHD (39) to determine their specific relevance in tGVHD. We found that inducible costimulator (ICOS) and glucocorticoid-induced TNF receptor (GITR) were dispensable for tGVHD (Figure 7C), whereas costimulatory molecule Ox40 was required for tGVHD (Figure 7C). Interestingly, both ablation and overexpression of carcinoembryonic antigen-associated cell adhesion molecule 1 (Ceacam1), a net negative regulator of $\mathrm{T}$ cell function, were able to attenuate tGVHD (Figure 7C).

We further assessed the role of the costimulatory molecule Ox 40 for tGVHD because of its functions as an activator of both Teffs and Tregs. We performed experiments by mixing T effector cells (Teffs) and Tregs from WT and $O x 40^{-/-}$FoxP3-GFP mice in a 1:4 ratio to assess the relative importance of $\mathrm{Ox} 40$ on Teff versus Treg for tGVHD. We observed that recipients of $O x 40^{-1-}$ Teffs have increased numbers of donor $\mathrm{CD}^{+} \mathrm{CD}^{+}(\mathrm{DP})$ thymocytes compared with recipients of WT Teffs (Figure 7D). These experiments suggest that while Ox40 expression on Teffs is important for donor T cells to mediate tGVHD, Ox40 expression on donor Tregs is dispensable.

\section{Discussion}

The organ specificity of GVHD has been attributed in part to conditioning-associated tissue damage, numbers and types of antigen-presenting cells, local levels of cytokines and chemokines, as well as the differential use by alloreactive T cells of trafficking, costimulatory/coinhibitory, and cytolytic pathways (39). However, the relevance of specific molecules within these pathways and the interactions between donor alloactivated $\mathrm{T}$ cells and host thymic stromal cells in tGVHD have not been extensively studied. Here, we use a library of genetically modified mice and antibody reagents to address these questions and show that, as with the gut, liver, and skin, damage to the thymus is mediated by a highly specific set of molecules that regulate multiple aspects of $\mathrm{T}$ cell function. Our work represents the first in-depth study to our knowledge of both the pathways used by alloreactive T cells to mediate tGVHD as well as the target cell subsets in the thymus that are involved and their reciprocal interactions. Additionally, we address the kinetics of tGVHD onset, the reversibility of tGVHD over time as a function of donor $\mathrm{T}$ cell dose, and the relative sensitivity of the thymus as well as its function in the context of systemic and clinical GVHD.

Our study suggests that tGVHD can be viewed as a spatially and temporally regulated series of steps. First, the radiation component of allo-BMT-conditioning regimens induces thymic stromal cells, particularly epithelial cells, to upregulate the death receptors Fas and DR5 and, at the same time, to downregulate cFLIP, a negative regulator of extrinsic apoptosis through both of these pathways (Figure 6B) (40). This sensitizes the thymus to damage from $\mathrm{T}$ cells via FasL and TRAIL as well as potentially via soluble DR5 agonists.

Second, there is a relatively rapid infiltration of donor $\mathrm{T}$ cells into the thymus, which begins by days 4 to 6 after transplant, peaks with a maximal number of $\mathrm{T}$ cells on day 14 (Figure 2, A and $\mathrm{C}$ ), and declines to low but persistent numbers in the thymus by days $21-28$. This is reminiscent of alloactivated $T$ cell trafficking into the gut (41) but slower in its kinetics. We found that both canonical thymic-trafficking molecules, such as PSGL-1, as well as molecules thought to be primarily relevant for gut trafficking, such as integrin subunit $\beta_{7}$, were ultimately important for the disease course of tGVHD.

Third, there is a selective activation of donor $\mathrm{T}$ cells through regulation of costimulation and coinhibition (via molecules such as $\mathrm{Ox} 40$ and Ceacam 1), followed by specific cytolysis of thymic stromal cells via the Fas/FasL and TRAIL/DR5 pathways, ultimately leading to derangements in thymus cytoarchitecture as defined by thymic cortical thinning, obliteration of the corticomedullary junction, and decreased thymic cellularity (Figure 1, H and I, and Figure 5, B and C).

Earlier studies have shown that radiation causes rapid and transient neutrophilic infiltration of the thymus and early appearance of donor-type antigen-presenting cells $(42,43)$. Conditioning radiation may enable early infiltration of alloreactive $T$ cells, as we observed in our model system, and additionally could change strict requirements for the usual homing molecules. Our studies of trafficking molecules involved in tGVHD revealed that in addition to molecules, such as CCR9, L selectin, and PSGL-1, which have been directly implicated in thymus trafficking in other physiological and pathophysiological settings (31-34), molecules thought to be primarily important for $\mathrm{T}$ cell gut trafficking and gastrointestinal GVHD, such as CCR2, CXCR3, and the $\alpha_{\mathrm{E}}$ and $\beta_{7}$ integrin subunits (36-38), were also relevant for tGVHD. It is difficult to address whether the involvement of gut-trafficking molecules in tGVHD represents a direct thymus-trafficking requirement or whether these molecules allowed $\mathrm{T}$ cells to first efficiently traffic to the intestines (e.g., on days 2 to 3 ) and subsequently undergo generalized alloactivation and expansion before entering the thymus. Our studies of the integrin $\beta_{7}$ subunit, which is a classic "guthoming" molecule, versus PSGL-1, which has been implicated in "thymus-homing," suggest that both effects may be relevant. However, the end result of decreased tGVHD and increased numbers of donor BM-derived $\mathrm{CD}^{+} \mathrm{CD}^{+}$thymocytes in recipients of $\mathrm{T}$ cells deficient for both thymus and gut-trafficking molecules suggests that both sets of molecules are either directly or indirectly involved in $\mathrm{tGVHD}$ and disease severity.

Although multiple costimulatory and coinhibitory molecules have been shown to be relevant for systemic and target organ GVHD, our studies suggest that, in contrast to their relevance in gut, liver, or 
skin GVHD, the molecules ICOS and GITR $(44,45)$ were dispensable for tGVHD. We did observe, however, that the TNF-family costimulatory molecule $\mathrm{Ox} 40$ was relevant for Teffs but not Tregs to mediate tGVHD. Similar to our studies of T cell-trafficking molecules, the selective requirements for specific costimulatory and coinhibitory molecules in tGVHD may indicate either a direct interaction of $\mathrm{T}$ cells with target cells within the thymus or a more general role for these molecules in regulating $\mathrm{T}$ cell alloactivation.

Finally, upon studying donor alloactivated T cell cytolytic pathways, we were surprised to note that TNF, which is important for skin and gastrointestinal GVHD, is dispensable for tGVHD in our model systems. We also noted that perforin, which is required for gut GVHD, is also dispensable for tGVHD, in agreement with previous studies by Levy and colleagues $(46,47)$. Also in agreement with this group's previous study, we found that Fas/FasL interactions were important for tGVHD (46). Interestingly, TRAIL, which we have previously shown to be predominantly important for GVT activity (29), was important for donor alloreactive T cells to mediate tGVHD. These observations were true both at comparatively low doses of donor $\mathrm{T}$ cells as well as at higher doses (Figure 3, compare A and B).

Our studies with TRAIL analogs indicate that the posttransplant thymus is exquisitely sensitive to TRAIL/DR5-mediated damage (Figure 4). Surprisingly, despite the absence of donor alloreactive $T$ cells, these mice exhibited a significant decrease in total as well as donor $\mathrm{CD}^{+} \mathrm{CD}^{+}(\mathrm{DP})$ thymocyte numbers, as compared with recipients of control hamster IgG, as well as a decrease in thymic export. This suggests that the presence of TRAIL analogs, which can agonize the DR5 receptor even in the setting of T cell-depleted allo-BMT, is sufficient to cause damage to the thymus in the absence of donor alloreactive $\mathrm{T}$ cells, their other cytolytic pathways, or the proinflammatory cytokines associated with the conditioning regimen and GVHD onset. Taken together, this disparity in cytolytic pathways that damage gastrointestinal tissues, the skin, and the thymus may be one reason why "subclinical" GVHD can still be associated with disruption of thymopoiesis and delayed $\mathrm{T}$ cell reconstitution after transplant.

In our studies, for which we used a low dose of T cells, we have discriminated the $\mathrm{T}$ cell pathways that are required for the trafficking, activating, and cytolytic functions in the thymus and the target stromal cells subsets that are most affected by GVHD. Here we also highlight how even very small numbers of donor $\mathrm{T}$ cells, constituting less than $1 \%$ of total donor leukocytes, may cause minimal mortality or clinical GVHD, yet still damage the thymus, its cytoarchitecture, and its function, both in MHC-mismatched as well as MHC-matched minor antigen-disparate model systems (Figure 1 and Supplemental Figure 3). Indeed, tGVHD may be directly or indirectly associated with decreased proliferative capacity of peripheral donor $T$ cells. Furthermore, our data are supported by a recent report from Tsao et al., which compared purified hematopoietic progenitor cells (devoid of mature T cells) with T cell-replete whole BM: this study showed that purified progenitor populations give superior lymphoid reconstitution and function, particularly of the lymph nodes, likely through a mechanism by which donor alloreactive $T$ cells mediate subclinical GVHD in the periphery (48). Consequently, even small numbers of donor alloactivated T cells, which cause mild or minimal clinical GVHD, may still be clinically important and associated with impaired thymopoiesis, immune reconstitution, and delayed $\mathrm{T}$ lineage reconstitution and function after allo-BMT, via both central and peripheral mechanisms.
In additional studies, we explored the reversibility of tGVHD in experiments with a longer follow-up period (to 60 days). Interestingly, our results are in agreement with a recent report on clinical tGVHD in young allo-BMT patients by Clave et al., which measured peripheral blood counts and $\mathrm{T}$ cell receptor excision circles as an indicator of thymic function (49). In both our murine model systems and this report on tGVHD in humans, the process was transient: in our model systems, although recipients of low doses of donor alloreactive T cells had marked GVHD at day 28 after transplant (Figure 1C), by day 60 after transplant, recipients of up to $10^{5}$ donor $\mathrm{T}$ cells exhibited largely recovered total thymocytes counts (Supplemental Figure 4A).

The majority of our results agree with previous studies of $\mathrm{T}$ cell trafficking, regulation, and cytolysis in $\operatorname{GVHD}(30,37,44,50,51)$. In particular, previous studies by Levy and colleagues in the MHCmatched minor antigen-disparate model B6 $\rightarrow$ C3H.SW have shown that FasL, but not perforin, is required for GVHD-associated thymic atrophy (46). In addition, our work agrees with that of Hollander and colleagues, who have found that thymic epithelial cells are the primary target cells in vitro and in GVHR model systems (22). This is further validated by the work of Blazar, Hollander, and colleagues, who have shown that keratinocyte growth factor (which acts on thymic epithelial cells) may be cytoprotective in the thymus, and suggests one therapeutic strategy for the clinical prophylaxis or treatment of $\operatorname{tGVHD}(23,24,52)$.

However, our results differ from previous reports in the relevance of TNF, Fas/FasL, and IFN- $\gamma$ for tGVHD, which we attribute to model-dependent effects $(21,22,53-55)$. Our model systems depart from most previous reports: due to the sensitivity of the thymus to GVHD (Figure 1C and Supplemental Figure 3D), we selected a low dose of $0.25 \times 10^{6}$ donor T cells, which caused relatively little GVHD mortality or morbidity, but largely chose stringent MHC-disparate models, which included radiation-containing-conditioning regimens that we show to be an important initiator of tGVHD, by sensitizing thymic stroma to apoptotic stimuli. By contrast, most previous studies have employed either (a) a higher dose of T cells to elicit disease; (b) different model systems, such as parent $\rightarrow$ F1 or MHC-matched minor antigen-disparate strain combinations; (c) nonirradiated GVHR systems; or (d) in vitro techniques.

We conclude that even small numbers of donor alloreactive T cells, which are insufficient to cause classical "clinical GVHD," are nonetheless sufficient to damage the thymus, thereby impairing $\mathrm{T}$ lineage reconstitution and peripheral donor $\mathrm{T}$ cell function. Consequently, improved clinical $\mathrm{T}$ cell depletion strategies and strategies that block TRAIL and FasL-mediated apoptosis or their common downstream pathways may mitigate tGVHD and improve thymopoiesis and donor T cell function after an allogeneic BMT.

\section{Methods}

Mice. Mice were housed in microisolator cages in Memorial Sloan-Kettering Cancer Center's specific pathogen-free facilities and received autoclaved sterile drinking water and standard chow. WT C57BL/6J (B6, H-2 $\left.{ }^{\mathrm{b}}\right), \mathrm{B} 6$ CD45.1, B6 Thy1.1, BALB/c (H-2 $\left.{ }^{\mathrm{d}}\right)$, BALB/c Thy1.1, LP (H-2 $)$, FVB (H-2q), B6D2F1 (H-2 $\left.{ }^{\mathrm{b} / \mathrm{d}}\right)$, E selectin (Sele $\left.e^{--}\right)$, FasL-deficient generalized lymphoproliferative disease ( $g l d)$, Fas receptor-deficient $l p r$, IFN- $\gamma\left(\mathrm{Ifng}^{-/-}\right)$, perforin $\left(\mathrm{Pfp}^{-/-}\right)$, and P selectin (Selp $\left.\mathrm{p}^{--}\right)$mice on the B6 background were obtained from The Jackson Laboratory. $\mathrm{Crr}^{-/-}$mice on the $\mathrm{B} 6$ background were a gift from P. Love (NIH, Bethesda, Maryland, USA). CD2-CC1-Tg (Ceacam1$\mathrm{Tg}$ ) mice, Ceacam $1^{-1-} \mathrm{B} 6$, and BALB/c mice were provided by N. Beauchemin 
(McGill Cancer Center). Ceacam1 1/- mice are ablated for all Ceacam1 isoforms $(56,57)$. $\operatorname{~cos}^{-1-}$ mice on the B 6 background were obtained from R. Flavell (Yale University, New Haven, Connecticut, USA). L selectin $\left(\right.$ Sell $\left.^{--}\right)$mice on the B6 background were obtained from T. Tedder (Duke University). B6 luciferase ${ }^{+}$/EGFP-transgenic mice were obtained from R. Negrin (Stanford University, Palo Alto, California, USA). memTNF mice were obtained from DNAX corporation. Psgl1 ${ }^{-/}$mice (58) on the B6 background were obtained from Bruce and Barbara Furie (Beth Israel Deaconess Medical Center, Boston, Massachusetts, USA). RAG2-EGFP mice on the FVB background (H-2q) were obtained from M. Nussenzweig (Rockefeller University, New York, New York, USA). Tnf/- mice on the B6 background were obtained from L. Old (Memorial Sloan-Kettering Cancer Center). Trail $/-$ mice on the B6 background were obtained from Immunex Corp. B6 FoxP3-GFP mice were generated in the laboratory of A. Rudensky (Memorial Sloan-Kettering Cancer Center), and B6 FoxP3-GFP/Ox40-/- mice were generated in the laboratory of A. Houghton (Memorial Sloan-Kettering Cancer Center). Trail $/-/$ gld double-deficient mice and Trail $/-/ g l d / T n f /-$ triple-deficient mice were created for this project by O.M. Smith (Memorial Sloan-Kettering Cancer Center) and backcrossed for 10 generations on a B6 background. Ceacam1-Tg mice were generated in our laboratory and constitutively overexpress the Ceacam1-4L isoform on all somatic NK and $\mathrm{T}$ cells under the control of the human $\mathrm{CD} 2$ promoter. Briefly, the CC1- $4 \mathrm{~L}$ cDNA, expressing 4 Ig domains and the long cytoplasmic domain, was inserted into the unique EcoR1 site within the VAhCD2 vector containing the hCD2 promoter and 2 polyadenylation sites (PolyA1,2). The linearized construct was microinjected into B6 oocytes (Harlan Laboratories) to produce transgenic mice that were identified by Southern blot with a $1.3-\mathrm{kb}$ ${ }^{32} \mathrm{P}$-labeled probe. This probe cross-reacts with the endogenous Ceacam1, Ceacam2, and Ceacam10 genes and also identifies the 1.7-kb EcoR1-digested transgene. Ceacam $1-\mathrm{Tg}$ mice were additionally identified by PCR amplification of a 3 oligo CD2A2 within the hCD2 LCR region.

$B M T$. All transplantation protocols were reviewed and approved by the Memorial Sloan-Kettering Cancer Center IACUC. Transplantation protocols have been previously described (59). Briefly, femurs and tibias were removed aseptically from euthanized donors, and BM was obtained. T cells were depleted by incubation with anti-Thy 1.2 antibody for 40 minutes at $4{ }^{\circ} \mathrm{C}$, followed by incubation with Low-TOX-M rabbit complement (Cederlane Laboratories) for 40 minutes at $37^{\circ} \mathrm{C}$. In select experiments in which mice expressed the Thy 1.1 allele, we depleted T cells via anti-CD5 magnetic beads (Miltenyi Biotec). TCD-BM was analyzed for purity of residual contaminating T cells; following a single round of complement depletion, contaminating $\mathrm{T}$ cells constituted approximately $0.2 \%$ of all leukocytes, and following 2 rounds of complement depletion, contaminating $\mathrm{T}$ cells constituted approximately $0.1 \%$ of all leukocytes. For a TCD-BM graft of $5 \times 10^{6}$ cells, this represents approximately 5,000-10,000 contaminating $\mathrm{T}$ cells. In most experiments, congenic differences between the donor BM (B6 CD45.1) and donor T cells (B6 Thy 1.1, B6 CD45.1, or B6 CD45.2) allowed the 2 syngeneic cell populations to be distinguished by flow cytometry. Allo-BMT recipients received total body irradiation from a ${ }^{137} \mathrm{Cs}$ source as a split dose, 3 hours apart, and then received the allograft. Radiation doses for each recipient strain are indicated in the manuscript or figure legends as appropriate.

Lineage depletion of BM cells. For some experiments, BM was obtained aseptically from the femurs and tibias of donors, and lineage-positive cells were depleted using MACS according to the manufacturer's instructions (Miltenyi Biotec). Lineage-depleted BM cells typically contained less than $0.1 \%$ contaminating donor $\mathrm{T}$ cells as measured by FITC-conjugated anti-CD3e staining.

Magnetic selection of donor splenic T cells and potential influence of donor B cells in $t G V H D$. We purified donor $\mathrm{T}$ cells from the spleens of B6.WT or B6.KO mice with positive selection, using $\mathrm{CD}^{+}$magnetic beads with the MACS system (Miltenyi Biotec). Typical purities were more than $90 \%$ by flow cytometry with FITC-conjugated anti-CD3r. To exclude the influence of a small number of $\mathrm{CD}^{+}$donor B cells from our studies of tGVHD, we assessed the purity of the resultant purified $\mathrm{T}$ cell grafts, and found that $\mathrm{CD}^{+}$selection alone typically resulted in a graft, which contained approximately $2 \% \mathrm{~B} 220^{+}$or $\mathrm{CD} 19^{+} \mathrm{B}$ cells (Supplemental Figure 1A). Magnetic depletion of $\mathrm{B} 220^{+}$cells before positive $\mathrm{CD} 5$-selection resulted in donor grafts with less than $0.2 \%$ contaminating donor $\mathrm{T}$ cells (Supplemental Figure 1A). Recipients of allo-BMT that received $\mathrm{T}$ cell allografts with or without $\mathrm{B}$ cell depletion showed similar severity in tGVHD as measured by a decrease in donor $\mathrm{BM}$-derived $\mathrm{CD} 45.1^{+} \mathrm{CD} 4^{+} \mathrm{CD} 8{ }^{+}$thymocyte count relative to recipients of TCD-BM alone (Supplemental Figure 1B), suggesting that the small number of B cells in a typical allograft do not significantly influence the development of tGVHD.

Monitoring of GVHD. All transplanted mice were monitored daily for survival and weekly for weight loss and clinical GVHD (fur and skin pathology, motility, hunching, and weight loss greater than 10\%), using a semiquantitative score as previously described (25). Mice with a summed score greater than 5 were considered moribund and euthanized.

Antibodies, dyes, cell staining, and flow cytometry. For analysis of thymocytes or splenic $\mathrm{T}$ cells, cells were stained with $\mathrm{H}-2 \mathrm{~K}^{\mathrm{b}}$ (clone AF6-88.5; BD Biosciences), H-2Dd (clone 34-2-12; BD Biosciences), Thy 1.1 (clone OX-7; BD Biosciences), CD45 (clone 30-F11; BD Biosciences), CD45.1 (clone A20; BD Biosciences), CD3ع (clone 145-2C11; BD Biosciences), CD4 (clone RM4-5 or GK1.5; BD Biosciences), CD8 (clone 53-6.7; BD Biosciences), CD25 (clone PC61; BD Biosciences), CD44 (clone IM7; Invitrogen), CD62L (clone MEL-14; BD Biosciences), DR5 (clone MD5-1; eBioscience), TRAIL (clone N2B2; BD Biosciences), and FasL (clone MFL3; BD Biosciences). For analysis of thymic stroma, cells were stained with UEA-1 (polyclonal; Vector Laboratories), Ly51/6C3 (clone BP-1; BD Biosciences), PDGFR1 (clone APB5; eBioscience), CD4 (clone RM4-5; BD Biosciences), CD8 (clone 53-6.7; $\mathrm{BD}$ Biosciences), $\mathrm{CD} 11 \mathrm{~b}$ (clone M1/70; BD Biosciences), CD11c (clone HL3 or N418; BD Biosciences), CD31 (clone 390; BD Biosciences), CD45 (clone 30-F11; BD Biosciences), MHC class II (clone M5/114.15.2; eBioscience), and c-FLIP (rabbit polyclonal; Abcam) and DR5 (clone MD5-1; eBioscience). FACS staining was performed as previously described (60). Intracellular staining was performed as previously described per the manufactures' directions (60).

Cells were labeled with CFSE as described previously (60). Antibody reagents and dyes were obtained from $\mathrm{BD}$ Biosciences, eBioscience Inc., Biolegend, Vector Laboratories, and AbCam. Samples were acquired on a Becton-Dickinson LSR II with DiVA version 6.1 software and analyzed in FlowJo version 8.7 (Treestar Inc.).

The DR5-1 hybridoma (61) was provided by H. Yagita (Juntendo University School of Medicine, Tokyo, Japan), and the Memorial Sloan-Kettering Cancer Center Monoclonal Antibody Core Facility generated endotoxinfree DR5-1 antibody for in vivo administration. Endotoxin-free hamster IgG control antibody was obtained from Bio XCell.

Thymic stromal cell digest. Thymi were digested as previously described (62). Briefly, thymi were removed from the thoracic cavities of sacrificed animals, cleaned of fat and connective tissues, cut radially to release free thymocytes, and incubated repeatedly in baths of collagenase D $(0.15 \%$ $\mathrm{w} / \mathrm{v})$ and DNAse I $(0.01 \% \mathrm{w} / \mathrm{v})$ in RPMI 1640 plus $10 \% \mathrm{FCS}$, with periodic mechanical agitation until completely digested. Fractions containing cells were then collected and centrifuged before analysis.

Bioluminescent imaging. Animals received $150 \mathrm{mg} / \mathrm{kg}$ D-Luciferin (Xenogen) via i.p. injection. Ten to fifteen minutes later, mice were anesthetized with isoflurane and placed in the Xenogen IVIS bioluminescence imaging system for analysis. Heatmap images depicting the whole body distribution of bioluminescent signals were superimposed on conventional grayscale photographs. 
Histopathologic analysis, keratin staining, and microscopy. Thymi were fixed using $4 \%$ paraformaldehyde for 24 to 48 hours and transferred to $70 \%$ ethanol for storage until use. Thymi were then embedded in paraffin. Sections of $4-\mu \mathrm{m}$ thickness were cut using a Leica Cryotome. The sections were stained using H\&E to observe the tissue morphology. To distinguish between the cortex and the medulla by immunofluorescence, paraffin sections were stained using K5 (catalog no. PRB-160P; Covance) and K8 (Troma-1; Developmental Studies Hybridoma Bank) (Service de Genetique Cellulaire, Institute Pasteur) antibodies and detected with a Discovery XT processor from Ventana Medical Systems. Sections were visualized using a Zeiss Axioplan 2 Imagining microscope or scanned via a Mirax Scanner (Zeiss).

For objective analysis of cortical-medullary junction features, the percentage of cortical area, or K5/K8 staining and cortical thickness, each individual thymus was sectioned 3 times through various parts of the organ, which were $50 \mu \mathrm{m}$ apart from each other. To assess cortical area, the percentage of the cortex as an index for cortical thinning was determined for all 3 sections via the following formula: ([total area - medulla area]/ total area) $\times 100$. Each percentage was averaged for the individual thymus.

Mirax Viewer (Zeiss) and Metamorph software (Molecular Devices) were used for quantification and analysis.

Anti-CD3 and anti-CD28 stimulation. Ninety-six-well plates were coated with anti-CD3 antibody (clone 145-2C11, BD Biosciences; $10 \mu \mathrm{g} / \mathrm{ml}$ ) and anti-CD28 antibody (clone 37.51, BD Biosciences; $10 \mu \mathrm{g} / \mathrm{ml}$ ) for $90 \mathrm{~min}$ ute at $37^{\circ} \mathrm{C}$ in PBS and washed 3 times with ice-cold PBS prior to use. Then, $10^{5} \mathrm{rbc}$-depleted $\mathrm{CD} 5$-selected splenic $\mathrm{T}$ cells were added to each well. Cells were incubated for 24 hours at $37^{\circ} \mathrm{C}$ under $5 \% \mathrm{CO}_{2}$ and then pulsed with $1 \mu \mathrm{Ci}$ of ${ }^{3} \mathrm{H}$ thymidine. Thymidine incorporation was measured at 18 hours as CPM.

Mixed lenkocyte reaction. Stimulator cells were splenocytes of B6, BALB/c, or B10.BR origin and were depleted of $\mathrm{CD}^{+} \mathrm{T}$ cells by magnetic selection and $\mathrm{rbc}$ by hypotonic lysis, and then irradiated with $20 \mathrm{~Gy}$ from a ${ }^{60} \mathrm{Co}$ source. Responder cells were magnetically selected for $\mathrm{CD}^{+} \mathrm{T}$ cells from spleens. Then, $10^{5}$ stimulators and $10^{5}$ responders were incubated for 5 days at $37^{\circ} \mathrm{C}$ under $5 \% \mathrm{CO}_{2}$ and then pulsed with $1 \mu \mathrm{Ci}$ of ${ }^{3} \mathrm{H}$ thymidine. Thymidine incorporation was measured at 18 hours as CPM, and stimulation indices were calculated as described in the figure legends.

Statistics. Calculations were performed in GraphPad Prism version 5.0 (GraphPad Software) or Excel 2008 (Microsoft Corp.) Survival curves were analyzed with the Mantel-Cox test. All other comparisons were made with the Mann-Whitney $U$ test unless specified. A $P$ value of less than 0.05 was considered statistically significant.

\section{Acknowledgments}

The authors thank the staff of the Memorial Sloan-Kettering Cancer Center Research Animal Resources Center for excellent animal care and the staff of the Molecular Cytology Core Facility and Comparative Pathology Laboratories for assistance with sample preparation and microscopy. The authors thank Bruce Furie and Barbara Furie (Beth Israel Deaconess Medical Center, Division of Hemostasis and Thrombosis) for the gift of the Psgl1 ${ }^{-/-}$mouse; Hideo Yagita (Juntendo University School of Medicine, Department of Immunology, Central Laboratory of Medical Science) for the gift of anti-mDR5-1 agonistic antibody; Susan Prockop (Memorial Sloan-Kettering Cancer Center, Department of Pediatrics) for valuable discussion; Eric Pamer, Chao Shi, and Ingrid Leiner (Memorial Sloan-Kettering Cancer Center, Department of Infectious Diseases) for experimental assistance; and Kevin Bampoe (Memorial Sloan-Kettering Cancer Center, Department of Immunology and Medicine) for experimental assistance. This research was supported by NIH grants RO1-HL069929 (to M.R.M. van den Brink), R01-CA107096 (to M.R.M. van den Brink), R01-AI080455 (to M.R.M. van den Brink), and P01-CA33049 (to M.R.M. van den Brink). Support was also received by M.R.M. van den Brink from the Ryan Gibson Foundation (Dallas, Texas, USA), the Elsa U. Pardee Foundation (Midland, Michigan, USA), the Byrne Foundation (Etna, New Hampshire, USA), the Emerald Foundation (New York, New York, USA), the Experimental Therapeutics Center of Memorial Sloan-Kettering Cancer Center funded by Mr. William H. Goodwin and Mrs. Alice Goodwin, the Commonwealth Foundation for Cancer Research (Richmond, Virginia, USA), the Bobby Zucker Memorial Fund (Phoenixville, Pennsylvania, USA), and the Lymphoma Foundation (New York, New York, USA). N. Beauchemin was supported by the Canadian Institutes of Health Research. I.-K. Na and A. Ghosh are both supported by the Deutsche Krebshilfe, Mildred-Scheel-Stiftung. O. Penack was supported by the Deutsche Forschungsgemeinschaft. A.M. Holland is supported by NIH grant T32 AIO7621 and is a Starr Stem Cell Scholar Fellowship Awardee. R.R. Jenq is the recipient of grants from the American Association for Cancer Research MedImmune Fellowship for Research on Biologics-Based Therapies for Cancer (Philadelphia, Pennsylvania, USA) and the Leukemia \& Lymphoma Society Special Fellowship in Clinical Research (White Plains, New York, USA). This manuscript is solely the responsibility of the authors and does not necessarily represent the official views of the NIH. The funders had no role in study design, data collection and analysis, decision to publish, or preparation of the manuscript.

Received for publication August 7, 2009, and accepted in revised form October 7, 2009.

Address correspondence to: Marcel R.M. van den Brink, Memorial Sloan-Kettering Cancer Center, ZRC-1404, Mailbox 111, 1275 York Avenue, New York, New York 10065, USA. Phone: (646) 8882304; Fax: (917) 432-2375; E-mail: vandenbm@mskcc.org.
1. Ochs L, et al. Late infections after allogeneic bone marrow transplantations: comparison of incidence in related and unrelated donor transplant recipients. Blood. 1995;86(10):3979-3986.

2. Socie $G$, et al. Long-term survival and late deaths after allogeneic bone marrow transplantation. Late Effects Working Committee of the International Bone marrow Transplant Registry. NEnglJMed.1999; 341(1):14-21.

3. Maraninchi D, et al. Impact of T-cell depletion on outcome of allogeneic bone-marrow transplantation for standard-risk leukaemias. Lancet. 1987; 2(8552):175-178.

4. Roux E, et al. Recovery of immune reactivity after T-cell-depleted bone marrow transplantation depends on thymic activity. Blood. 2000;96(6):2299-2303.
5. Dumont-Girard F, et al. Reconstitution of the T-cell compartment after bone marrow transplantation: restoration of the repertoire by thymic emigrants. Blood. 1998;92(11):4464-4471.

6. Mackall CL, Gress RE. Pathways of T-cell regeneration in mice and humans: implications for bone marrow transplantation and immunotherapy. Immunol Rev. 1997;157:61-72.

7. Patel DD, et al. Thymic function after hematopoietic stem-cell transplantation for the treatment of severe combined immunodeficiency. N Engl J Med. 2000;342(18):1325-1332.

8. Hakim FT, et al. Constraints on CD4 recovery postchemotherapy in adults: thymic insufficiency and apoptotic decline of expanded peripheral CD4 cells. Blood. 1997;90(9):3789-3798.
9. Mackall CL, et al. Age, thymopoiesis, and CD4+ T-lymphocyte regeneration after intensive chemotherapy. N Engl J Med. 1995;332(3):143-149.

10. Small TN, et al. Comparison of immune reconstitution after unrelated and related T-cell-depleted bone marrow transplantation: effect of patient age and donor leukocyte infusions. Blood. 1999; 93(2):467-480.

11. Douek DC, et al. Assessment of thymic output in adults after haematopoietic stem-cell transplantation and prediction of T-cell reconstitution. Lancet. 2000;355(9218):1875-1881.

12. Weinberg K, Annett G, Kashyap A, Lenarsky C, Forman SJ, Parkman R. The effect of thymic function on immunocompetence following bone marrow transplantation. Biol Blood Marrow Transplant. 
1995;1(1):18-23.

13. Lapp WS, Ghayur T, Mendes M, Seddik M, Seemayer TA. The functional and histological basis for graftversus-host-induced immunosuppression. Immunol Rev. 1985;88:107-133.

14. Seemayer TA, Lapp WS, Bolande RP. Thymic involution in murine graft-versus-host reaction. Epithelial injury mimicking human thymic dysplasia. Am J Pathol. 1977;88(1):119-134.

15. Ghayur T, Seemayer TA, Xenocostas A, Lapp WS Complete sequential regeneration of graft-vs.-hostinduced severely dysplastic thymuses. Implications for the pathogenesis of chronic graft-vs.-host disease. Am J Pathol. 1988;133(1):39-46.

16. Seddik M, Seemayer TA, Lapp WS. T cell functional defect associated with thymid epithelial cell injury induced by a graft-versus-host reaction. Transplan tation. 1980;29(1):61-66.

17. van Ewijk W, et al. Thymic microenvironments, 3-D versus 2-D? Semin Immunol. 1999;11(1):57-64.

18. Hollander GA, Widmer B, Burakoff SJ. Loss of normal thymic repertoire selection and persistence of autoreactive T cells in graft vs host disease. J Immu nol. 1994;152(4):1609-1617.

19. van den Brink MR, Moore E, Ferrara JL, Burakoff SJ. Graft-versus-host-disease-associated thymic damage results in the appearance of $\mathrm{T}$ cell clones with anti-host reactivity. Transplantation. 2000; 69(3):446-449.

20. Krenger W, Rossi S, Hollander GA. Apoptosis of thymocytes during acute graft-versus-host disease is independent of glucocorticoids. Transplantation. 2000;69(10):2190-2193.

21. Krenger W, Rossi S, Piali L, Hollander GA. Thymic atrophy in murine acute graft-versus-host disease is effected by impaired cell cycle progression of host pro-T and pre-T cells. Blood. 2000;96(1):347-354.

22. Hauri-Hohl MM, et al. Donor T-cell alloreactivity against host thymic epithelium limits T-cell development after bone marrow transplantation. Blood. 2007;109(9):4080-4088.

23. Kelly RM, et al. Keratinocyte growth factor and androgen blockade work in concert to protect against conditioning regimen-induced thymic epithelial damage and enhance T-cell reconstitution after murine bone marrow transplantation. Blood. 2008;111(12):5734-5744.

24. Panoskaltsis-Mortari A, et al. Keratinocyte growth factor facilitates alloengraftment and ameliorates graft-versus-host disease in mice by a mechanism independent of repair of conditioning-induced tissue injury. Blood. 2000;96(13):4350-4356.

25. Cooke KR, et al. An experimental model of idiopathic pneumonia syndrome after bone marrow transplantation: $\mathrm{I}$. The roles of minor $\mathrm{H}$ antigens and endotoxin. Blood. 1996;88(8):3230-3239.

26. Hoffmann P, Ermann J, Edinger M, Fathman CG, Strober S. Donor-type CD4(+)CD25(+) regulatory $\mathrm{T}$ cells suppress lethal acute graft-versus-host disease after allogeneic bone marrow transplantation. J Exp Med. 2002;196(3):389-399.

27. Taylor PA, Lees CJ, Blazar BR. The infusion of ex vivo activated and expanded CD4(+)CD25(+) immune regulatory cells inhibits graft-versus-host disease lethality. Blood. 2002;99(10):3493-3499.

28. Schmaltz C, et al. Differential use of Fas ligand and perforin cytotoxic pathways by donor T cells in graft-versus-host disease and graft-versus-leukemia effect. Blood. 2001;97(9):2886-2895.

29. Schmaltz C, et al. T cells require TRAIL for optimal graft-versus-tumor activity. Nat Med. 2002; 8(12):1433-1437.

30. Dutt S, et al. L-selectin and beta7 integrin on donor CD4 $\mathrm{T}$ cells are required for the early migration to host mesenteric lymph nodes and acute colitis of graft-versus-host disease. Blood. 2005; 106(12):4009-4015.

31. Perry SS, et al. L-selectin defines a bone marrow analog to the thymic early T-lineage progenitor. Blood. 2004;103(8):2990-2996.

32. Perry SS, Welner RS, Kouro T, Kincade PW, Sun $\mathrm{XH}$. Primitive lymphoid progenitors in bone marrow with $\mathrm{T}$ lineage reconstituting potential. J Immunol. 2006;177(5):2880-2887.

33. Rossi FM, et al. Recruitment of adult thymic progenitors is regulated by $\mathrm{P}$-selectin and its ligand PSGL-1. Nat Immunol. 2005;6(6):626-634.

34. Uehara S, Grinberg A, Farber JM, Love PE. A role for CCR9 in T lymphocyte development and migration. J Immunol. 2002;168(6):2811-2819.

35. Duffner U, et al. Role of CXCR3-induced donor T-cell migration in acute GVHD. Exp Hematol. 2003 31(10):897-902.

36. El-Asady R, et al. TGF-\{beta\}-dependent CD103 expression by CD8(+) T cells promotes selective destruction of the host intestinal epithelium during graft-versus-host disease. J Exp Med. 2005; 201(10):1647-1657

37. Petrovic A, et al. LPAM (alpha 4 beta 7 integrin) is an important homing integrin on alloreactive $\mathrm{T}$ cells in the development of intestinal graft-versus-host disease. Blood. 2004;103(4):1542-1547.

38. Waldman E, et al. Absence of beta7 integrin results in less graft-versus-host disease because of decreased homing of alloreactive $\mathrm{T}$ cells to intestine. Blood. 2006;107(4):1703-1711.

39. Shlomchik WD. Graft-versus-host disease. Nat Rev Immunol. 2007;7(5):340-352.

40. Budd RC, Yeh WC, Tschopp J. cFLIP regulation of lymphocyte activation and development. Nat Rev Immunol. 2006;6(3):196-204.

41. Beilhack A, et al. In vivo analyses of early events in acute graft-versus-host disease reveal sequential infiltration of T-cell subsets. Blood. 2005; 106(3):1113-1122.

42. Longo DL, Davis ML. Early appearance of donortype antigen-presenting cells in the thymuses of $1200 \mathrm{R}$ radiation-induced bone marrow chimeras correlates with self-recognition of donor I region gene products. J Immunol. 1983;130(6):2525-2527.

43. Uchimura E, Watanabe $N$, Niwa O, Muto $M$, Kobayashi Y. Transient infiltration of neutrophils into the thymus in association with apoptosis induced by whole-body X-irradiation. J Leukoc Biol. 2000;67(6):780-784.

44. Hubbard VM, et al. Absence of inducible costimulator on alloreactive $\mathrm{T}$ cells reduces graft versus host disease and induces Th2 deviation. Blood. 2005;106(9):3285-3292.

45. Muriglan SJ, et al. GITR activation induces an opposite effect on alloreactive CD4(+) and CD8(+) $\mathrm{T}$ cells in graft-versus-host disease. J Exp Med.
2004;200(2):149-157.

46. Baker MB, Riley RL, Podack ER, Levy RB. Graft-versus-host-disease-associated lymphoid hypoplasia and $\mathrm{B}$ cell dysfunction is dependent upon donor T cellmediated Fas-ligand function, but not perforin function. Proc Natl Acad Sci U S A. 1997;94(4):1366-1371.

47. van den Brink MR, Burakoff SJ. Cytolytic pathways in haematopoietic stem-cell transplantation. Nat Rev Immunol. 2002;2(4):273-281.

48. Tsao GJ, Allen JA, Logronio KA, Lazzeroni LC, Shizuru JA. Purified hematopoietic stem cell allografts reconstitute immunity superior to bone marrow. Proc Natl Acad Sci U S A. 2009;106(9):3288-3293

49. Clave E, et al. Acute graft-versus-host disease transiently impairs thymic output in young patients after allogeneic hematopoietic stem cell transplantation. Blood. 2009;113(25):6477-6484.

50. Borsotti C, et al. Absence of donor T-cell-derived soluble TNF decreases graft-versus-host disease without impairing graft-versus-tumor activity. Blood. 2007;110(2):783-786.

51. Terwey $\mathrm{TH}$, et al. CCR2 is required for CD8induced graft-versus-host disease. Blood. 2005; 106(9):3322-3330

52. Rossi S, et al. Keratinocyte growth factor preserves normal thymopoiesis and thymic microenvironment during experimental graft-versus-host disease. Blood. 2002;100(2):682-691.

53. Schmaltz C, et al. Donor T cell-derived TNF is required for graft-versus-host disease and graft-versus-tumor activity after bone marrow transplantation. Blood. 2003;101(6):2440-2445.

54. van Den Brink MR, et al. Fas-deficient lpr mice are more susceptible to graft-versus-host disease. Jimmunol. 2000;164(1):469-480.

55. van den Brink MR, et al. Fas ligand-deficient gld mice are more susceptible to graft-versus-host-disease. Transplantation. 2000;70(1):184-191.

56. Blau DM, et al. Targeted disruption of the Ceacam 1 (MHVR) gene leads to reduced susceptibility of mice to mouse hepatitis virus infection. J Virol. 2001;75(17):8173-8186

57. Hemmila E, et al. Ceacam $1 \mathrm{a}^{-/-}$mice are com pletely resistant to infection by murine coronavirus mouse hepatitis virus A59. J Virol. 2004; 78(18):10156-10165

58. Yang J, et al. Targeted gene disruption demonstrates that P-selectin glycoprotein ligand 1 (PSGL-1) is required for P-selectin-mediated but not E-selectin-mediated neutrophil rolling and migration. J Exp Med. 1999;190(12):1769-1782.

59. Alpdogan O, et al. IL-7 enhances peripheral T cell reconstitution after allogeneic hematopoietic stem cell transplantation. J Clin Invest. 2003; 112(7):1095-1107.

60. Alpdogan SO, et al. Rapidly proliferating CD44hi peripheral $\mathrm{T}$ cells undergo apoptosis and delay posttransplantation $\mathrm{T}$-cell reconstitution after allogeneic bone marrow transplantation. Blood. 2008;112(12):4755-4764.

61. Takeda K, et al. Induction of tumor-specific T cell immunity by anti-DR5 antibody therapy. J Exp Med. 2004;199(4):437-448.

62. Gray DH, Chidgey AP, Boyd RL. Analysis of thymic stromal cell populations using flow cytometry. Jimmunol Methods. 2002;260(1-2):15-28. 